\title{
The Multilayered Nature of Reference Selection
}

\author{
María-del-Mar Camacho-Miñano \\ Financial Economics and Accounting II Department, Complutense University, Campus of Somosaguas, \\ 28223-Pozuelo de Alarcón, Madrid, Spain.E-mail:marcamacho@ccee.ucm.es

\begin{abstract}
Manuel Núñez-Nickel
Business Administration Department, Carlos III University, C/Madrid, 126, 28903-Getafe, Madrid,
\end{abstract} \\ Spain.E-mail:mnunez@emp.uc3m.es
}

\begin{abstract}
Why authors choose some references in preference to others is a question that is still not wholly answered despite its being of interest to scientists. The relevance of references is twofold: They are a mechanism for tracing the evolution of science, and because they enhance the image of the cited authors, citations are a widely known and used indicator of scientific endeavor. Following an extensive review of the literature, we selected all papers that seek to answer the central question and demonstrate that the existing theories are not sufficient: Neither citation nor indicator theory provides a complete and convincing answer. Some perspectives in this arena remain, which are isolated from the core literature. The purpose of this article is to offer a fresh perspective on a 30-year-old problem by extending the context of the discussion. We suggest reviving the discussion about citation theories with a new perspective, that of the readers, by layers or phases, in the final choice of references, allowing for a new classification in which any paper, to date, could be included.
\end{abstract}

\section{Introduction}

From the scientist's perspective, knowing the mechanisms that govern the choice of references is of interest for at least two reasons. First, a citation (of a reference) comprises the essential unit of information, one that allows for the progress of science to be followed (Cozzens, 1985, p. 136). Therefore, the only way to observe the progress of science is by knowing the original sources of ideas and how they later evolved (McInnis \& Symes, 1988; Price, 1963; Van Dalen \& Henkens, 1999). Second, not only do scientists' rewards, promotions, and research funds depend on the number of times that their papers are cited (and by whom and in which journals) but at the same time, the global analysis of citations is a general tool for evaluating and managing the level of science in many countries (Aksnes, 2006, p. 177). This is based on a range

Received September 17, 2007; revised November 23, 2008; accepted November 24, 2008 of criteria such as the ranking of journals, obtaining funds for research subjects, evaluation of universities, the impact of papers, and maps of science (Cano, 1989; Leydesdorff \& Amsterdamska, 1990; Nicolaisen, 2007; Snyder, Cronin, \& Davenport, 1995), despite the limitations of such methods (e.g., Coleman, 2007; MacRoberts \& MacRoberts, 1996; Marx \& Cardona, 2007; Száva-Kováts, 1994).

To date, the theories for explaining the selection of references are not convincing (Baldi, 1998; Leydesdorff, 1998; Nicolaisen, 2004; Wouters, 1999a, 1999b), but there has been an increase in the number of publications on this subject, as can be seen in Figure 1. That is because it seems that this viewpoint screens other alternatives. In this sense, this is not a small problem because all papers that analyze nonmotivational factors are removed from this debate, and as a result, these are not included in any complete citation theory (van Raan, 1998). We seek to remedy this problem.

The aim of this article is to show that this controversy is simply the consequence of choosing the author's perspective as the unit of analysis. In other words, it is only a sublevel of selection in a choice process that is more globally referenced. With our new proposal, this controversy would be transformed through the analysis of author prejudices that modify a previous level of decision making, which depends on the function of the citation in the paper. The result of this model is a reclassification of all factors and papers that analyze this line of research. In relation to this, we have found 12 bibliographical surveys (Bar-Ilan, 2008; Brooks, 1988; Cozzens, 1981; Cronin, 1984; Liu, 1993b; Luukkonen, 1997; Moed, 2005; Nicolaisen, 2007; Sen, 1996; Small, 1982; Walling, 2005; H.D. White, 2004a); however, none make a theoretical analysis of the total stream as does this work.

The structure of the article is as follows. First, we describe the setting of the problem by means of an extensive bibliographical survey. Next, we present the core of our article-the proposition of our new selection model of citation as a contribution to a more integrated theory of references - and attempt to gather together all articles about citation behavior. Finally, we suggest future research and discuss the central focus. 


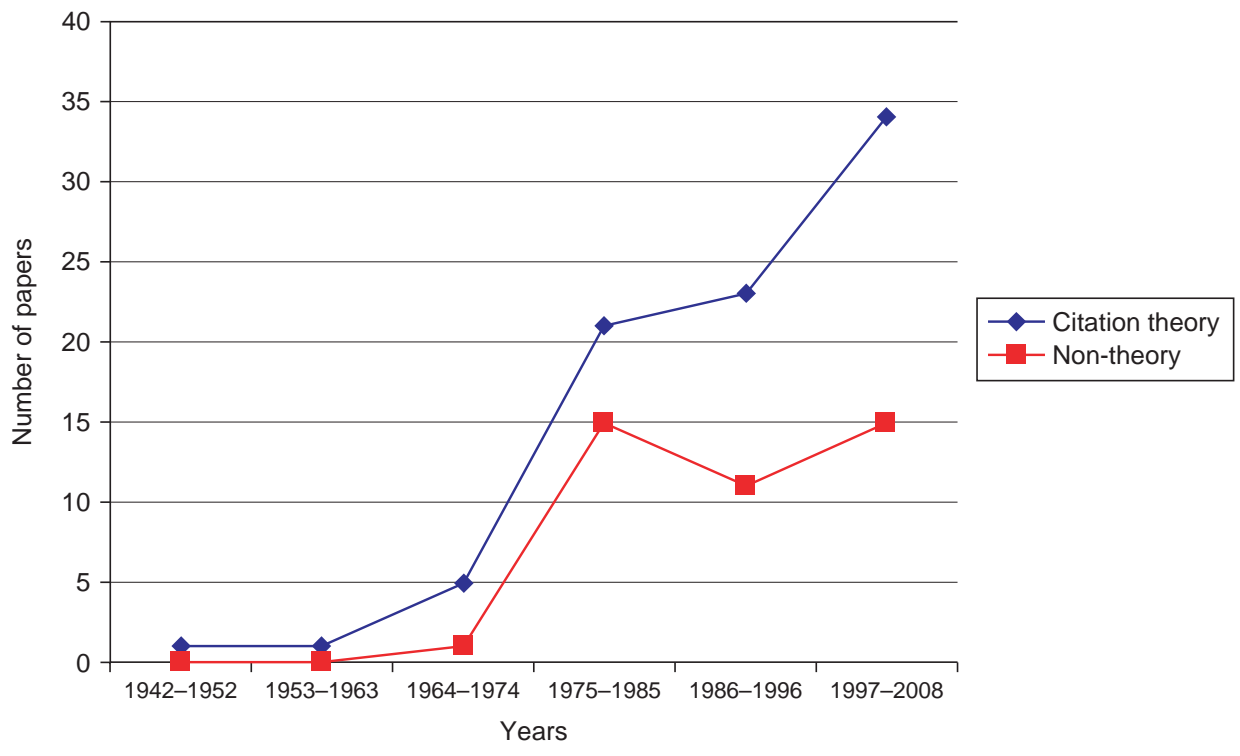

FIG. 1. Growth in number of papers about citations.

\section{Method}

We compiled all papers, books, and theses from several databases according to key words - citation studies, citation behaviors, citation theory, citation analysis, citation process, references, self-citations, evolution of science, and citation index - and selected all papers that answered the question of why authors cite (see Appendix). To our knowledge, at the present time, there are 127 papers related to the central theme of this article and 12 additional surveys named earlier (139 papers in total). Overall, there is a majority of empirical studies (78.7\%) as opposed to purely descriptive ones $(21.3 \%)$. These works are spread over 30 different journals (almost $47 \%$ between JASIST and Scientometrics) across nine branches of science, the most represented being information science $(21.6 \%)$ followed by science in general $(19.2 \%)$.

The foundation of Citation theory ${ }^{1}$ rests on the description of researchers' motivations for citing (Walling, 2005). The basis of the theory of citations comprises two alternatives: normative and social constructivist theories. The first theory is based on processes of production and validation of scientific knowledge, from an internal perspective, founded on the norms of science (Merton, 1942). The second theory rests on the social and economic conditioning of scientific production, from an external perspective, based upon the impact of journals, the prestige of authors, self-interest, or a target audience (Gilbert, 1977; Kaplan, 1965; Latour \& Woolgar, 1979). In other words, the influence of one paper within science depends on "what one says" in the normative view and on "who one is" in the constructivist view (Stewart, 1983). Between these two major theories, there is an eclectic position, or multidimensional approach, which confronts

\footnotetext{
${ }^{1}$ For explanations in detail, see Nicolaisen (2007).
}

critics of the normative position and defends citation analysis. This third approach views citation as a multifaceted process, but there is no original view of citation (Cozzens, 1989), although the multidimensional approach seems to show some convergence, according to empirical evidence (Rowlands, 1999).

From our review of the literature, it is unquestionably true that from all the articles in this research stream, there are 42 (33\% of the total) that cannot be classified into any one of the three existing citation theories (see Figure 1). Constructive theory provides a better, though still insufficient, explanation than the normative one of the findings of citation content and context studies about the functionality of citations (Luukkonen, 1997). That is, the controversy between normative and social constructivist theory does not offer a complete answer to the central question of this study. The theoretical explanation of the citing behavior of scientists through citation theory is not valid, but one is needed (Leydesdorff, 1998; van Raan, 1998; H.D. White, 2004a; W. White, 2001; Wouters, 1999a, 1999b).

Harter (1992) argued that the act of citing is a personal and psychological process, but from the perspective of relevance, it has been demonstrated that there is a sociocultural environment that contrasts with personal processes (Hjørland, 2002). Moreover, scientists in the same discipline tend to cite references from homogeneous sources (Cronin, 2000; Nicolaisen, 2004; Skilton, 2006), but not the same reference lists (Moed, 2005 , p. 212). Wouters (1998) believed that this is because of confusion between citation and reference. We demonstrate that citation theory does not embrace all papers that explain why scientists cite (see Appendix). Therefore, the alternative explanation of authors' referencing behavior through citation indicators is not suitable because it is impossible to link the sign citation to a specific behavioral citation (Martens, 2001; Wouters, 1999b). This is a semiotic view that considers a 
citation culture and nothing else. Another view of citation theory claims that authors are in general honest and use references to their inspirations and sources (Cronin, 2005; Nicolaisen, 2004; Rowlands, 1999). However, a global understanding of the nature of the reference and authors' reasons for citing is necessary for an evolutionary view (Moed, 2005; Nicolaisen, 2007). This is the foundation of our model: a selective process (Arunachalam, 1998; Cronin, 2005).

\section{Results: A Model of Selective Reference Choice by Layers}

In our opinion, the appeal, and subsequent success, of the controversy between normative and constructive theories arose because of the overly simple analysis of the reference phenomenon-that it is attributable to a single perspective: the author's pride. That is, the author could in theory believe that she or he is the only "free" decision maker and chooses to cite what she or he wishes; however, this reasoning is deceptive because it equates the choosing of information from which science evolves and the improving of the author's personal status. If this decision were neutral (i.e., without other restrictions), it would seem reasonable to take one attitude or another depending on personal ethics.

Nevertheless, another dimension of the same problem may be considered in line with Moed (2005). For instance, it should be remembered that if a scientist researches and publishes, it is because there is another fundamental actor in this relation who wishes to improve her or his wisdom: namely, the reader (Budd, 1999; Cronin, 2000; Garfield, 1980; Harwood, 2008; Kurtz et al., 2005). From the reader's perspective, it is slightly more difficult to justify a scientist citing a boss, coauthor, editor, reviewer, or friend instead of the real seminal papers (Aksnes, 2006). For this reason, we believe there is a multilayered selection process and limitations which impact on behavior before the final choice is made. In other words, an author's self-interested behavior is always possible when she or he believes that her or his actions can be hidden from readers.

We believe that an acceptable solution for showing this tendency is through a dynamic model of layers or phases. In this way, we can easily represent the importance of the decisions that an author makes up to the final reference selection. The first level is the external and objective limitations on an author's or reader's focus, which hinder or reduce the possibility of quoting sources. The second level, which we have named "functional selection" according to previous literature, is the first objective selection by authors from the totality of papers on the same theme, analyzed by function and utility. Finally, the last phase is the reference choice or "preferential selection." It seems clear that authors cannot cite all references when a large number exist (Marx \& Cardona, 2004) or when space is limited (Seglen, 1998, p. 225). Thus, they select specific papers depending on personal preferences. This last phase, therefore, is a subjective decision related to honesty. With this new focus, the constructivist theory is not the opposite of normative theory but is a sieve that retains one paper or another as a function of the author's personal prejudices. Figure 2 shows our reasoning in graphic form.

\section{Phase 1: External Limitations}

There are some limitations that reduce the probability of citing articles (Soper, 1976). If a paper or a document cannot be accessed, it is not ethical to quote it because it cannot be a source of ideas (Simkin \& Roychowdhury, 2003). We identify two basic restrictions on citation choice. The first restriction is access to information, which affects behavioral researchers (Schaffer, 2004). Some papers are impossible or difficult to obtain, or read. This problem has been reduced in importance thanks to the growth of digital technology (Lawrence, 2001). A related problem is the intellectual property restrictions that protect databases (Gardner \& Rosenbaum, 1998). The second restriction is language: Authors may be unable to understand a paper because they cannot read the language in which it is published (Cronin, 2005, p. 1507; Martens \& Goodrum, 2006, p. 332). In practice, non-English papers are less likely to be read because English is the tongue of science (Montgomery, 2004). For example, Korean papers are less likely to be cited by non-Korean scientists regardless of their quality (Kim, 2004).

\section{Phase 2: Functional Choice}

Once the author knows all usable papers, she or he needs to classify them by function. That is, each reference may be useful for demonstrating a particular point in the paper. In this way, citations justify the methodology, recount previous steps in the study, or are used simply to provide a particular definition or comment to develop hypotheses.

This second level in this choice is fundamental because authors need to elaborate their reasoning; however, the only requisite is to demonstrate the incremental knowledge that they contribute to science. It is not necessary to prove again all useful previous findings of earlier authors but simply to cite them to reinforce their own findings and convince readers of the logical truth of their ideas (Merton, 1968). We view this choice as objective, although it is a personal decision, because this choice has no moral implications but only depends on the ability of authors to identify the best sources in relation to their function in the paper (Krampen, Beker, Wahner, \& Montada, 2007). At this level of the selection process, the most interesting aspect is that authors are interested only in providing the information, which is most relevant to readers, and in providing more studies to elaborate their ideas. In short, they want to guarantee that their papers have sufficient quality to be published in journals. In other words, it could be said that authors select references from the readers' perspective.

The different functions that we have collated from the literature listed in the Appendix are summarized in Table 1. This table displays the concept and its explanation. If a citation does not inform readers, it is unnecessary and is called a "perfunctory citation." 


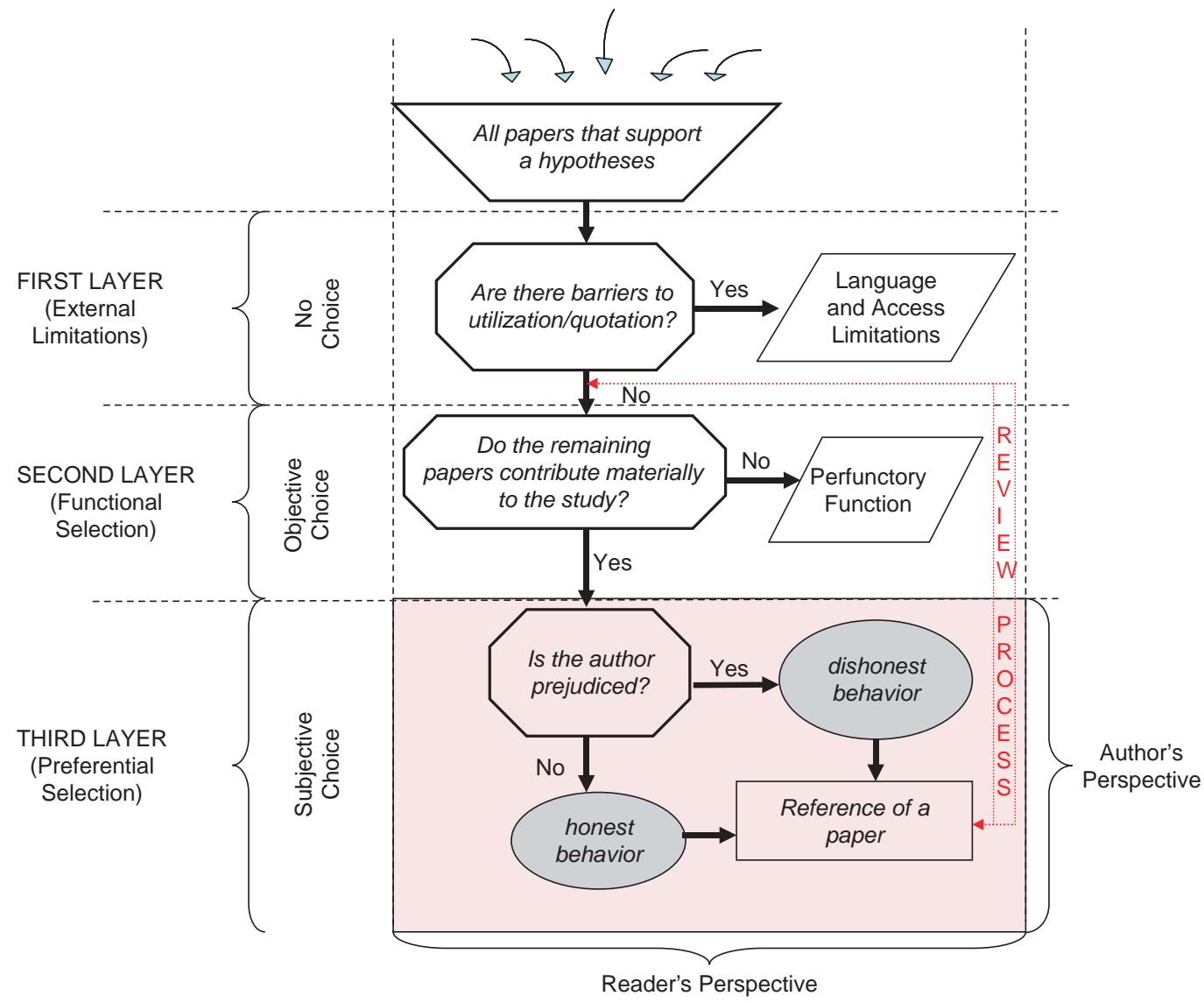

FIG. 2. Reference selection process.

TABLE 1. Functions of citations in the text.

\begin{tabular}{|c|c|}
\hline Function & Explanation \\
\hline Conceptual & Citation is useful for showing concepts, definitions, or interpretations, or for substantiating a statement or an assumption. \\
\hline Operational & $\begin{array}{l}\text { Citation contributes additional information, data, a point of comparison, a theoretical equation, or methodology. Results of the citing } \\
\text { article furnish a new interpretation/explanation of the data of the cited source, a methodology, or formulation of research problems. }\end{array}$ \\
\hline Organic & $\begin{array}{l}\text { Parts of relevant literature that are influential, essential, basic; descriptions of other relevant work. The results of the citing article prove, } \\
\text { verify, or substantiate data or interpretation of the cited source. }\end{array}$ \\
\hline Perfunctory & $\begin{array}{l}\text { Citation that is casual, unusual, neutral, or made with reservations, or for ceremonial purposes. It is included as a note or with no clear } \\
\text { indication of reasons. }\end{array}$ \\
\hline Evolutionary & Historical background; citations are mentioned in the introduction or discussion as part of the history and the state of the art. \\
\hline Juxtapositional & Additional information that is supplementary or illustrative. \\
\hline Confirmative & Cited source is positively evaluated, is of critical importance to results. \\
\hline Negational & $\begin{array}{l}\text { Cited source is negatively evaluated: partial or total negation; for example, when a theory or method is not applicable or not the best one, } \\
\text { the citation is made with criticism and another treatment is proposed by author. It could be with the aim of correction, discussion, } \\
\text { or disclaimer. }\end{array}$ \\
\hline Others & Alerting readers to forthcoming work, anticipated value, or new research. \\
\hline
\end{tabular}

\section{Phase 3: Preferential Selection}

In the process of citation choice, when authors have selected all useful papers for each function and seek to maximize the quality of their research, the third level is applied. It is possible that there are several (generally many) references that guarantee the same utility for each function. Because in most cases it is impossible and irrelevant to cite all of them, authors are obliged to choose those which they consider the best, or in the words of Nicolaisen (2004), the handicap. Here, the honesty of the authors has a role (Cronin, 2005; Merton, 1979; Nicolaisen, 2007). We consider this third step a truly subjective selection because it is from the author's perspective. There are some examples of an author's subjective reference choices being cryptomnesia or 
TABLE 2. Classification of types of prejudices in the literature review.

\begin{tabular}{ll}
\hline Types of prejudices & Subspecies of each type \\
\hline Author & $\begin{array}{c}\text { Numbers of authors, nationality, rank/status/ position, sex, social ties, university, specialty, age, degree, relative standings of } \\
\text { the collaborating authors, educational experience abroad, length of publishing career, position of syllabus author, institutional } \\
\text { status of author, cryptomnesia, obliteration by incorporation. } \\
\text { Impact factor, visibility, language, "window dressing," country, type of contents/topic/focus, size, frequency, reputation of } \\
\text { editorial board, circulation numbers, balance of trade, delay, time, age of journal, sponsorship, internationality, format, } \\
\text { online availability, target, publicity, journal spectrum. } \\
\text { Size/number of pages, number of years elapsed, order of articles in an issue, whether article is a comment/reply/note, } \\
\text { historical content, regional empirical focus, type of paper, sources, bibliography, access to paper. } \\
\text { Focus, type, originality, theoretical or empirical content, same subtopic, category of discipline, utility, usefulness appraisals, } \\
\text { standard reference/norms. } \\
\text { Regional specialization, total number of citations per paper, lack of citations, interest, novelty, utility, significance, social and } \\
\text { psychological factors, research channel, location of references. }\end{array}$ \\
Others &
\end{tabular}

citation amnesia (Garfield, 1980)—when an author does not recognize the original idea-or obliteration by incorporation (Merton, 1996, p. 30)—when some ideas are accepted, but authors are no longer cited. There is a question of honesty and a problem of acknowledging intellectual debts (Garfield, 2002).

We have called this phase "preferential selection" because although it could rest on strictly scientific criteria, it also is true that an author could have subjective prejudices. As an example, there could be providing the same definition, on which an author bases her or his reasoning. The scientific utility (i.e., the necessary function in the paper) is guaranteed; however, the paper published in the highest rated journal would make the topic seem more relevant. If the author of the cited paper is on the editorial board (if this situation occurred by chance), there would be an extra bonus because of the probability that she or he would review the paper. It also is true that one cites others to gain political advantage as part of the social process of knowledge construction (Latour, 2002); however, we would add that this occurs with the limitations discussed earlier. In this way, in contrast to Cozzens (1989), this view would partly invalidate the traditional controversy between normative and constructivist theories because the normative theory would assume our whole model from the first phase through to the third. But, looking for a simile, the constructivist theory would only permit the final choice of this third step. Therefore, the debate is narrowed down because authors do not face terrible moral and ethical dilemmas between scientifically correct references and those most profitable to their interests, but they simply choose among a group of similar papers according to their scientific utility. Depending on their prejudices (or susceptibility to external pressures), however, they make a final choice that benefits them. For this reason, the tension between normativist and constructivist theories is irrelevant, but what matters is the degree of prejudice among authors, research lines, or branches of science, as it was empirically demonstrated (Baldi, 1998; Leimu \& Koricheva, 2005).

Table 2 displays the most important prejudices.

One characteristic of this focus is that there is more interest in the consequences of citation (publishing in an important journal, receiving better consideration of a paper, or obtaining promotion) than in citation itself. In fact, this focus is the current tendency. However, this is a limited view because the sample is difficult to generalize to other subjects and because the importance of papers depends on sample size (Shadish, Tolliver, Gray, \& Gupta, 1995).

\section{Discussion and Future Research}

In this article, we argue from an empirical standpoint that although the research on citation is interesting, it does not offer a total explanation of this phenomenon. Our multilayered selection of references is a new perspective that clarifies several aspects. First, the constructivist theory is not the antithesis of the normative theory, as seems to be derived from previous literature, but it has a mediating effect. In this way, the question is not which theory is more powerful or whether the former exists but which has the greatest influence because it is certain that both have an impact.

Many interesting research questions arise from this new perspective. For instance, as discussed earlier, we find that prejudices may exist even in the best journals. However, authors also can detract from the quality in their own interest by means of self-citation (Lawani, 1982) or conditioning by groups of researchers (Wuchty, Jones, \& Uzzi, 2007). This is a delicate, but fundamental, issue; in other words, either the quality of papers is guaranteed or such prejudices will damage the development of science. In any case, it seems that prejudice is diametrically opposed to science, which should be totally objective. It requires honest referencing by authors that may be trusted by readers. Thus, it seems logical to believe that sexual, ethnic, and educational prejudices would be eliminated for the good of science. Therefore, it would be interesting not only to learn the degree of prejudice in each branch of science but also to discover mechanisms for completely eliminating these from research.

Another consequence of this dynamic model is the demonstration of the different perspectives that must be analyzed. This article studies only two perspectives: the author's and the reader's. We have shown how, by considering the author's 
focus, the model improves in depth and interest; however, although we have included these in the model, we have not forgotten another fundamental protagonist in this story: the editor. Latour (2002) considered the process of publication to be a strategic game among enemies and friends, and in this process, the editor is the bottleneck where all interests converge. For this reason, she or he is in the optimum position to avoid or promote reasonable behavior. On the other hand, an editor with a team of reviewers can encourage several kinds of prejudice. From this perspective, some other research questions arise. For instance, if the relationship between an author and an editor is considered a strategic game, then an equilibrium of interests may be founded between them. That is, there would be an optimal decision on the part of both the author and the editor, without neglecting the readers. However, we can only go so far. With this model, there could be a sensible analysis of how, by varying the conditions of the problem, certain behavior could be encouraged or eliminated.

\section{Acknowledgment}

We are deeply grateful by the suggestions of two anonymous referees, who highlighted important cross-references and caveats. We are indebted to them.

\section{References}

Ahmed, T., Johnson, B., Oppenheim, C., \& Peck, C. (2004). Highly cited old papers and the reasons why they continue to be cited: Part II. The 1953 Watson and Crick article on the structure of DNA. Scientometrics, 61(2), $147-156$.

Aksnes, D.W. (2003). A macro study of self-citation. Scientometrics, 56(2), 234-246.

Aksnes, D.W. (2006). Citation rates and perceptions of scientific contribution. Journal of the American Society for Information Science, 57(2), $169-185$.

Allen, B. (1997). Referring to schools of thought: An example of symbolic citations. Social Studies of Science, 27, 937-949.

Allen, B., Qin, J., \& Lancaster, F.W. (1994). Persuasive communities: A longitudinal analysis of references in the Philosophical Transactions of the Royal Society, 1665-1990. Social Studies of Science, 24, 279-310.

Amsterdamska, O., \& Leydesdorff, L. (1989). Citations: Indicators of significance? Scientometrics, 15(5/6), 449-471.

Arunachalam, S. (1998). Citation analysis. Do we need a theory? Scientometrics, 43(1), 141-142.

Baird, L.M., \& Oppenheim, C. (1994). Do citations matter? Journal of Information Science, 20(1), 2-15.

Baldi, S. (1998). Normative versus social constructivist processes in the allocation of citations: A network-analytic model. American Sociological Review, 63, 829-846.

Bar-Ilan, J. (2008). Informetrics at the beginning of the 21st century-A review. Journal of Informetrics, 2, 1-52.

Bavelas, J.B. (1978). The social psychology of citations. Canadian Psychological Review, 19(2), 158-163.

Bonzi, S. (1982). Characteristics of a literature as predictors of relatedness between cited and citing works. Journal of the American Society for Information Science, 33(4), 208-216.

Bonzi, S., \& Snyder, H.W. (1991). Motivations for citation-A comparison of self citation and citation to others. Scientometrics, 21(2), 245-254.

Brooks, T.A. (1985). Private acts and publics objects: An investigation of citer motivations. Journal of the American Society for Information Science, 36(4), 223-229.
Brooks, T.A. (1986). Evidence of complex citer motivations. Journal of the American Society for Information Science, 37(1), 34-36.

Brooks, T.A. (1988). Citer motivations. Encyclopaedia of Library and Information Science, 43, 48-59.

Budd, J.M. (1999). Citations and knowledge claims: Sociology and knowledge as a case in point. Journal of Information Science, 25(4), 265-274.

Cano, V. (1989). Citation behavior-Classification, utility, and location. Journal of the American Society for Information Science, 40(4), 284-290.

Case, D.O., \& Higgins, G.M. (2000). How can we investigate citation behaviour? A study of reasons for citing literature in communication. Journal of the American Society for Information Science, 51(7), 635-645.

Christensen-Szalanski, J.J.J., \& Beach, L.R. (1984). The citation bias: Fad and fashion in the judgment and decision literature. American Psychologist, January, 75-78.

Chubin, D.E., \& Moitra, S.D. (1975). Content analysis of references: Adjunct or alternative to citation counting? Social Studies of Science, 5(4), 423-441.

Cole, S. (1975). The growth of scientific knowledge in the book. In L.A. Coser (Ed.), The idea of the social structure: Papers in honour of Robert K. Merton (pp. 175-220). New York: Harcourt, Brace, Jovanovich.

Coleman, A. (2007). Assessing the value of a journal beyond the impact factor. Journal of the American Society for Information Science and Technology, 58(8), 1148-1161.

Cozzens, S.E. (1981). Taking the measure of science: A review of citation theories. ISSK Newsletter on the New Directions in the Sociology of Science, 7, 16-21.

Cozzens, S.E. (1985). Comparing the sciences: Citation context analysis of papers from neuropharmacology and the sociology of science. Social Studies of Science, 15, 127-153.

Cozzens, S.E. (1989). What do citations count? The rhetoric-first model. Scientometrics, 15(5/6), 437-447.

Cronin, B. (1981). The need for a theory of citing. Journal of Documentation, 37, 16-24.

Cronin, B. (1984). The citation process. The role and significance of citations in scientific communication. London: Taylor Graham.

Cronin, B. (1994). Tiered citation and measures of document similarity. Journal of the American Society for Information Science, 45(7), 537-538.

Cronin, B. (1998). Metatheorizing citation. Scientometrics, 43(1), 45-55.

Cronin, B. (2000). Semiotics and evaluative bibliometrics. Journal of Documentation, 56(4), 440-453.

Cronin, B. (2005). A hundred million acts of whimsy? Current Science, 89(9/10), 1505-1509.

Dolman, H., \& Bodewitz, H. (1985). Sedimentation of a scientific concept: The use of citation data. Social Studies of Science, 15, 507-523.

Duncan, E.B., Anderson, F.D., \& Mcaleese, R. (1981, April). Qualified citation indexing: Its relevance to educational technology. In E. Duncan \& R. McAleese (Eds.), Information retrieval in educational technology. Proceedings of the 1st Symposium on Information Retrieval in Educational Technology (pp. 70-79). Aberdeen, Scotland: University of Aberdeen.

Finney, B. (1979). The reference characteristics of scientific tests. Unpublished master's thesis, London: Centre for Information Science, City University. [Not available direct access]

Frost, C.O. (1979). The use of citations in literary research: A preliminary classification of citation functions. Library Quarterly, 49(4), 399-414.

Gardner, W., \& Rosenbaum, J. (1998). Intellectual property: Database protection and access to information. Science, 281(5378), 786-787.

Garfield, E. (1977). Can citation indexing be automated? Essays of an Information Scientist, 1, 84-90. Philadelphia: ISI Press. (Original work published 1965)

Garfield, E. (1979). Citation indexing: Its theory and applications in science, technology and humanities. New York: Wiley.

Garfield, E. (1980). From citation amnesia to bibliographic plagiarism. Essays of an Information Scientist, 4, 503-507.

Garfield, E. (1996). When to cite. Library Quarterly, 66(4), 449-458.

Garfield, E. (1998). Random thoughts on citationology. Its theory and practice. Scientometrics, 43(1), 69-76. 
Garfield, E. (2002). Demand citation vigilance. The Scientist, 16(2), 6.

Gilbert, G.N. (1977). Referencing as persuasion. Social Studies of Science, $7(1), 113-122$.

Hanney, S., Frame, I., Grant, J.A., Buxton, M., Young, T., \& Lewison, G. (2005). Using categorisations of citations when assessing the outcomes from health research. Scientometrics, 65(3), 357-379.

Harter, S.P. (1992). Psychological relevance and information-science. Journal of the American Society for Information Science, 43(9), 602-615.

Harwood, N. (2008). Citers' use of citees' names: Findings from a qualitative interview-based study. Journal of the American Society for Information Science and Technology, 59(6), 1007-1011.

Herlach, G. (1978). Can retrieval of information form citation indexes be simplified? Journal of the American Society for Information Science, 29(6), 308-310.

Hjørland, B. (2002). Epistemology and the socio-cognitive perspective in information science. Journal of the American Society for Information Science, 53(4), 257-270.

Hodges, T.L. (1972). Citation indexing: Its potential for bibliographical control. Doctoral dissertation, University of California, Berkeley.

Hooten, P.A. (1991). Frequency and functional use of cited documents in information-science. Journal of the American Society for Information Science, 42(6), 397-404.

Hutson, S.R. (2002). Gendered citation practice in "American Antiquity" and other archaeology journals. American Antiquity, 67(2), 331-347.

Hyland, K. (2003). Self-citation and self-reference-Credibility and promotion in academic publication. Journal of the American Society for Information Science and Technology, 54(3), 251-259.

Ioannidis, P.A. (2005). Contradicted and initially stronger effects in highly cited clinical research. Journal of the American Medical Association, 294(29), 218-228.

Kaplan, N. (1965). The norms of citation behavior: Prolegomena to the footnote. American Documentation, 16, 179-184.

Kim, H.J. (2000). Motivations for hyperlinking in scholarly electronic articles: A qualitative study. Journal of the American Society for Information Science, 51(10), 887-899.

Kim, K. (2004). The motivation for citing specific references by social scientists in Korea: The phenomenon of co-existing references. Scientometrics, 59(1), 79-93.

Kjaergard, L.L., \& Gluud, C. (2002). Citation bias of hepato-biliary randomized clinical trials. Journal of Clinical Epidemiology, 55, 407-410.

Kostoff, R.N. (1998). The use and misuse of citation analysis in research evaluation-Comments on theories of citation? Scientometrics, 43(1), $27-43$.

Krampen, G., Beker, R., Wahner, U., \& Montada, L. (2007). On the validity of citation counting in science evaluation: Content analyses of references and citations in psychological publications. Scientometrics, 71(2), 191-202.

Kuch, T.D.C. (1978). Predicting the citedness of scientific papers: Objective correlates of citedness in the American Journal of Physiology. Proceedings of the ASIS annual meeting, 15, 185-187.

Kurtz, M.J., Eichhorn, G., Accomazzi, A., Grant, C., Demleitner, M., Murray, S.S., et al. (2005). The bibliometric properties of article readership information. Journal of the American Society for Information Science, 56(2), 111-128.

Lancaster, F.W., Lee, S.Y.K., \& Diluvio, C. (1990). Does place of publication influence citation behaviour? Scientometrics, 19(3-4), 239-244.

Lancaster, F.W., Porta, M.A., Plagenz, K., Szymborski, K., \& Krebs, M. (1986). Factors influencing sources cited by scientists: A case study for Cuba. Scientometrics, 10(5/6), 243-257.

Latour, B. (1987). Science in action [Spanish version, 1992]. Barcelona: Labor.

Latour, B. (2002). Science in action. Cambridge, MA: Harvard University Press.

Latour, B., \& Woolgar, S. (1979). Laboratory life. The construction of scientific facts. New York: Sage [Spanish version, 1995]. Madrid: Alianza Editorial.

Law, J., \& Williams, R.J. (1982). Putting facts together: A study of scientific persuasion. Social Studies of Science, 12, 535-558.
Lawani, S.M. (1982). On the heterogeneity and classification of author selfcitations. Journal of the American Society for Information Science, 33(5), 281-284.

Lawrence, S. (2001). Online or invisible? Nature, 411(6837), 521.

Leimu, R., \& Koricheva, J. (2005). What determines the citation frequency of ecological papers? Trends in Ecology and Evolution, 20(1), 28-32.

Leydesdorff, L. (1998). Theories of citation? Scientometrics, 43(1), 5-25.

Leydesdorff, L., \& Amsterdamska, O. (1990). Dimensions of citation analysis. Science Technology \& Human Values, 15(3), 305-335.

Lipetz, B. (1965). Improvement of the selectivity of citation indexes to science literature through inclusion of citation relationship indicators. American Documentation, 16(2), 81-90.

Liu, M.X. (1993a). A study of citing motivation of Chinese scientists. Journal of Information Science, 19(1), 13-23.

Liu, M.X. (1993b). Progress in documentation-The complexities of citation practice-A review of citation studies. Journal of Documentation, 49(4), 370-408.

Lui, Z. (1997). Citation theories in the framework of international flow of information: New evidence with translation analysis. Journal of the American Society for Information Science, 48(1), 80-87.

Luukkonen, T. (1989). Publish in a visible journal or perish-Assessing citation performance of Nordic cancer-research. Scientometrics, 15(5-6), 349-367.

Luukkonen, T. (1990). Bibliometrics and evaluation of research performance. Annals of Medicine, 22(3), 145-150

Luukkonen, T. (1997). Why has Latour's theory of citations been ignored by the bibliometric community? Discussion of sociological interpretations of citation analysis. Scientometrics, 38(1), 27-37.

Macroberts, M.H., \& Macroberts, B.R. (1984). The negational reference: Or the art of dissembling. Social Studies of Science, 14, 91-94.

Macroberts, M.H., \& Macroberts, B.R. (1986). Quantitative measures of communication in science: A study of the formal level. Social Studies of Science, 16, 151-172.

Macroberts, M.H., \& Macroberts, B.R. (1987). Another test of the normative theory of citing. Journal of the American Society for Information Science, 38(4), 305-306.

Macroberts, M.H., \& Macroberts, B.R. (1988). Author motivation for not citing influences-A methodological note. Journal of the American Society for Information Science, 39(6), 432-433.

Macroberts, M.H., \& MacRoberts, B.R. (1996). Problems of citation analysis. Scientometrics, 36(3), 435-444.

Macroberts, M.H., \& Macroberts, B.R. (1997). Citation content analysis of a botany journal. Journal of the American Society for Information Science, 48(3), 274-275.

Maricic, S., Spaventi, J., Pavicic, L., \& Pifat-Mrzljak, G. (1998). Citation context versus the frequency counts of citation histories. Journal of the American Society for Information Science, 49(6), 530-540.

Martens, B.V.V. (2001). Do citation systems represent theories of truth? Information Research, 6(2). Retrieved August 1, 2008, from http://InformationR.net/ir/6-2/paper92.html

Martens, B.V.V., \& Goodrum, A.A. (2006). The diffusion of theories: A functional approach. Journal of the American Society for Information Science and Technology, 57(3), 330-341.

Marx, W., \& Cardona, M. (2004). Blasts from the past. Retrieved August 1, 2008, from http://physicsworld.com/cws/article/print/18921

Marx, W., \& Cardona, M. (2007). The citation impact outside referencesFormal versus informal citations [E-print]. Retrieved August 1, 2008, from http://arxiv.org/ftp/physics/papers/0701/0701135.pdf

Mccain, K.W., \& Turner, K. (1989). Citation context analysis and aging patterns of journal articles in molecular-genetics. Scientometrics, 17(1-2), $127-163$.

McInnis, R.G., \& Symes, D. (1988). David Riesman and the concept of bibliographic citation. College and Research Libraries, 49, 387-399.

Merton, R.K. (1942). Science and technology in a democratic order. Journal of Legal and Political Sociology, 1, 115-126.

Merton, R.K. (1957). Priorities in scientific discovery: A chapter in the sociology of science. American Sociological Review, 22(6), 635-659. 
Merton, R.K. (1968). The Matthew Effect in science. Science, 159(3810), 56-63.

Merton, R.K. (1979). Foreword by Eugene Garfield: Citation indexingIts theory and application in science, technology, and humanities. Philadelphia: ISI Press. Retrieved December 30, 2008, from http:// www.garfield.library.upenn.edu/ci/ foreword.pdf

Merton, R.K. (1988). The Matthew Effect in Science: II. Cumulative advantage and the symbolism of intellectual property. ISIS, 79, 606-623.

Merton, R.K. (1996). On social structure and science. Chicago: University of Chicago Press. [ISBN 0-226-52071-4, Google Print, p. 30]

Moed, H.F. (2005). Citation analysis in research evaluation. Dordrecht, The Netherlands: Springer.

Moed, H.F., \& Garfield, E. (2004). In basic science the percentage of "authoritative" references decreases as bibliographies become shorter. Scientometrics, 60(3), 295-303.

Montgomery, S. (2004). Of towers, walls and fields: Perspectives on language in science. Science, 303(5662), 1333-1335.

Moravcsik, M.J. (1988). Citation context classification of a citation classic concerning citation context classification. Social Studies of Science, 18, 515-521.

Moravcsik, M.J., \& Murugesan, P. (1975). Some results on the function and quality of citations. Social Studies of Science, 5, 86-92.

Moravcsik, M.J., Murugesan, P., \& Shearer, E. (1976). An analysis of citation patterns in Indian physics. Science and Culture, 42(6), 295-301.

Murugesan, P., \& Moravcsik, M.J. (1978). Variation of the nature of citation measures with journals and scientific specialties. Journal of the American Society for Information Science, 29(3), 141-147.

Nicolaisen, J. (2002). The J-shaped distribution of citedness. Journal of Documentation, 58(4), 383-395.

Nicolaisen, J. (2004). Social behavior and scientific practice: Missing pieces of the citation puzzle. Unpublished doctoral dissertation, Royal School of Library and Information Science, Copenhagen, Denmark.

Nicolaisen, J. (2007). Citation analysis. Annual Review of Information Science and Technology, 41, 609-641.

Oppenheim, C., \& Renn, S.P. (1978). Highly cited old papers and the reasons why they continue to be cited. Journal of the American Society for Information Science, 29, 225-231.

Paul, D. (2000). In citing chaos: A study of the rhetorical use of citations. Journal of Business and Technical Communication, 14(2), 185-218.

Peritz, B.C. (1983). A classification of citation role for the social sciences and related fields. Scientometrics, 5, 303-312.

Pichappan, P., \& Sarasvady, S. (2002). The other side of the coin: The intricacies of author self-citations. Scientometrics, 54(2), 285-290.

Prabha, C.G. (1983). Some aspects of citation behaviour: A pilot study in business administration. Journal of the American Society for Information Science, 34(3), 202-206.

Price, D.J. (1963). Little science, big science. New York: Columbia University Press.

Rice, R.E., \& Crawford, G.A. (1993). Context and content of citations between communication and library and information science articles. In J.R. Schement \& B.D. Ruben (Eds.), Between communication and information (pp. 189-217). New Brunswick, NJ: Transaction Publishers.

Rousseau, R. (1992). Why am I not cited or why are multi-authored papers more cited than others? Journal of Documentation, 48(1), 79-80.

Rousseau, R. (1998). Citation analysis as a theory of friction or polluted air? Comments on theories of citation? Scientometrics, 43(1), 63-67.

Rowlands, I. (1999). Patterns of author cocitation in information policy: Evidence of social, collaborative and cognitive structure. Scientometrics, 44(3), 533-546.

Ruff, I. (1979). Citation analysis of a scientific career: A case study. Social Studies of Sciences, 9, 81-90.

Schaffer, T. (2004). Psychology citations revisited: Behavioral research in the age of electronic resources. Journal of Academic Librarianship, 30(5), 354-360.

Seglen, P.O. (1998). Citation rates and journal impact factors are not suitable for evaluation of research. Acta Orthopaedica Scandinavica, 69(3), 224-229.
Sen, S.K. (1990). A theoretical glance at citation process. International Forum on Information and Documentation, 15(1), 1-7.

Sen, S.K. (1996). Theoretical issues in citation process: A review. International Journal of Scientometrics and Informetrics, 2(2/3), 159-198.

Sengen, P.O. (1998). Citation rates and journal impact factors are not suitable for evaluation of research. Acta Orthopaedica Scandinavica, 68(3), 224-229.

Shadish, W.R., Tolliver, D., Gray, M., \& Gupta, S.K.S. (1995). Author judgments about works they cite: Three studies from psychology journals. Social Studies of Science, 25(3), 477-498.

Simkin, M.V., \& Roychowdhury, V.P. (2003). Read before you cite! Complex Systems, 14. Retrieved August 1, 2008, from http://arxiv.org/abs/ cond-mat/0212043

Skilton, P.H. (2006). A comparative study of communal practice: Assessing the effects of taken-for-grantedness on citation practice in scientific communities. Scientometrics, 68(1), 73-96.

Small, H. (1982). Citation context analysis. In B. Dervin \& M.J. Voigt (Eds.), Progress in communication science (pp. 287-310). Norwood, NJ: Ablex.

Small, H. (2004a). On the shoulders of Robert Merton: Towards a normative theory of citation. Scientometrics, 60(1), 71-79.

Small, H. (2004b). Why authors think their papers are highly cited. Scientometrics, 60(3), 305-316.

Small, H., \& Grenlee, E. (1980). Citation context analysis of a co-citation cluster: Recombinant-DNA. Scientometrics, 2(4), 277-301.

Small, H.G. (1978). Cited documents as concept symbols. Social Studies of Science, 8, 321-340.

Smith, A.J., \& Goodman, N.W. (1997). The hypertensive response to intubations. Do researchers acknowledge previous work? Canadian Journal of Anaesthesia, 44(1), 9-13.

Snyder, H., Cronin, B., \& Davenport, E. (1995). What's the use of citation: Citation analysis as a literature topic in selected disciplines of the social-sciences. Journal of Information Science, 21(2), 75-85.

Snyder, H.W., \& Bonzi, S. (1988). An enquiry into the behaviour of author self citation. Proceedings of the ASIS annual meeting, 25, 152-159.

Soper, M.E. (1976). Characteristics and use of personal collections. Library Quarterly, 46(4), 397-415.

Spiegel-Rösing, I. (1977). Bibliometrics and content analysis. Social Studies of Science, 7(1), 97-113.

Stewart, J.A. (1983). Achievement and ascriptive processes in the recognition of scientific articles. Social Forbes, 62(1), 166-189.

Swales, J. (1986). Citation analysis and discourse analysis. Applied Linguistics, 7(1), 39-56.

Swanson, D.R. (1977). Information retrieval as a trial-and-error process. Library Quarterly, 47(2), 128-148.

Száva-Kováts, E. (1994). Non-indexed eponymal citedness (NIEC): First fact-finding examination of a phenomenon of scientific literature. Journal of Information Science, 20(1), 55-70.

Tagliacozzo, R. (1977). Self-citations in scientific literature. Journal of Documentation, 33(4), 251-265.

Thorne, F.C. (1977). The citation index: Another case of spurious validity. Journal of Clinical Psychology, 33(4), 1157-1161.

Van Dalen, H.P., \& Henkens, K. (1999). How influential are demography journals? Population and Development Review, 25(2), 229-251.

Van Dalen, H.P., \& Henkens, K. (2001). What makes a scientific article influential? The case of demographers. Scientometrics, 50(3), 455-482.

Van Dalen, H.P., \& Henkens, K. (2005). Signals in science: On the importance of signalling in gaining attention in science. Scientometrics, 64(2), 209-233.

van Raan, A.F.J. (1998). In matters of quantitative studies of science the fault of theorists is offering too little and asking too much. Scientometrics, 43(1), 129-139.

Vinkler, P. (1987). A quasi-quantitative citation model. Scientometrics, 12(1-2), 47-72.

Vinkler, P. (1998). Comparative investigation of frequency and strength of motives toward referencing, the reference threshold model-Comments on theories of citation? Scientometrics, 43(1), 107-127. 
Walling, J.A. (2005). Bibliometric methods: Pitfalls and possibilities. Basic \& Clinical Pharmacology \& Toxicology, 97(5), 261-275.

Wang, P., \& White, M.D. (1995, October). Document use during a research project: A longitudinal study. Proceedings of the 58th ASIS annual meeting (pp. 181-188). Chicago: Medford.

Wang, P., \& White, M.D. (1996). A qualitative study of scholars' citation behaviour. Proceedings of the ASIS meeting, 33, 255-261.

Wang, P., \& White, M.D. (1999). A cognitive model of document use during a research project: Study II. Decisions at the reading and citing stages. Journal of the American Society for Information Science, 50(2), 98-114.

Weinstock, M. (1971). Citation indexes. In A. Kent (Ed.), Encyclopaedia of library on information science (Vol. 5, pp. 16-40). New York: Dekker.

White, H.D. (2004a). Citation analysis and discourse analysis revisited. Applied Linguistics, 25(1), 89-116.

White, H.D. (2004b). Reward, persuasion, and the Sokal Hoax: A study in citation identities. Scientometrics, 60(1), 93-120.

White, H.D., Wellman, B., \& Nazer, N. (2004). Does citation reflect social structure? Longitudinal evidence f-om the "Globenet" interdisciplinary research group. Journal of the American Society for Information Science and Technology, 55(2), 111-126.

White, M.D., \& Wang, P.L. (1997). A qualitative study of citing behaviour: Contributions, criteria, and metalevel documentation concerns. Library Quarterly, 67(2), 122-154.

White, W. (2001). Authors as citers over time. Journal of the American Society for Information Science and Technology, 52(2), 87-108

Wouters, P. (1998). The signs of science. Scientometrics, 41(1/2), 225-241.

Wouters, P. (1999a). Beyond the Holy Grail: From citation theory to indicator theory. Scientometrics, 44(3), 561-580.

Wouters, P. (1999b). The citation culture. Unpublished doctoral dissertation, University of Amsterdam.

Wuchty, S., Jones, B.F., \& Uzzi, B. (2007). The increasing dominance of teams in production of knowledge. Science, 316(5827), 1036. [DOI: 10.1126/science.1136099]

Zuckerman, H. (1987). Citation analysis and the complex problem of intellectual influence. Scientometrics, 12(5-6), 329-338. 


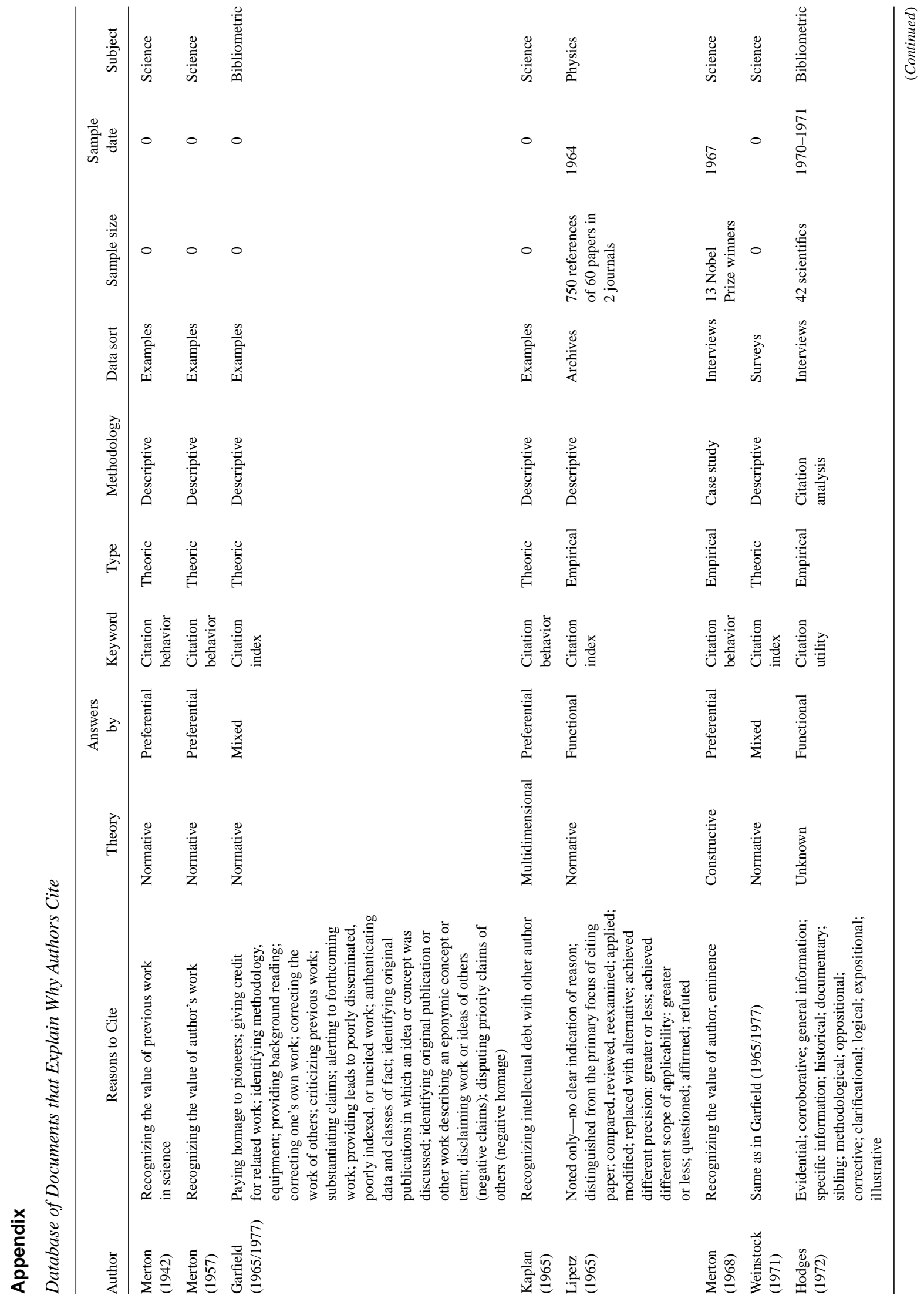

This is a preprint of an article accepted for publication in Journal of the American Society for Information Science and Technology copyright @ 2009 (American Society for Information Science and Technology) 


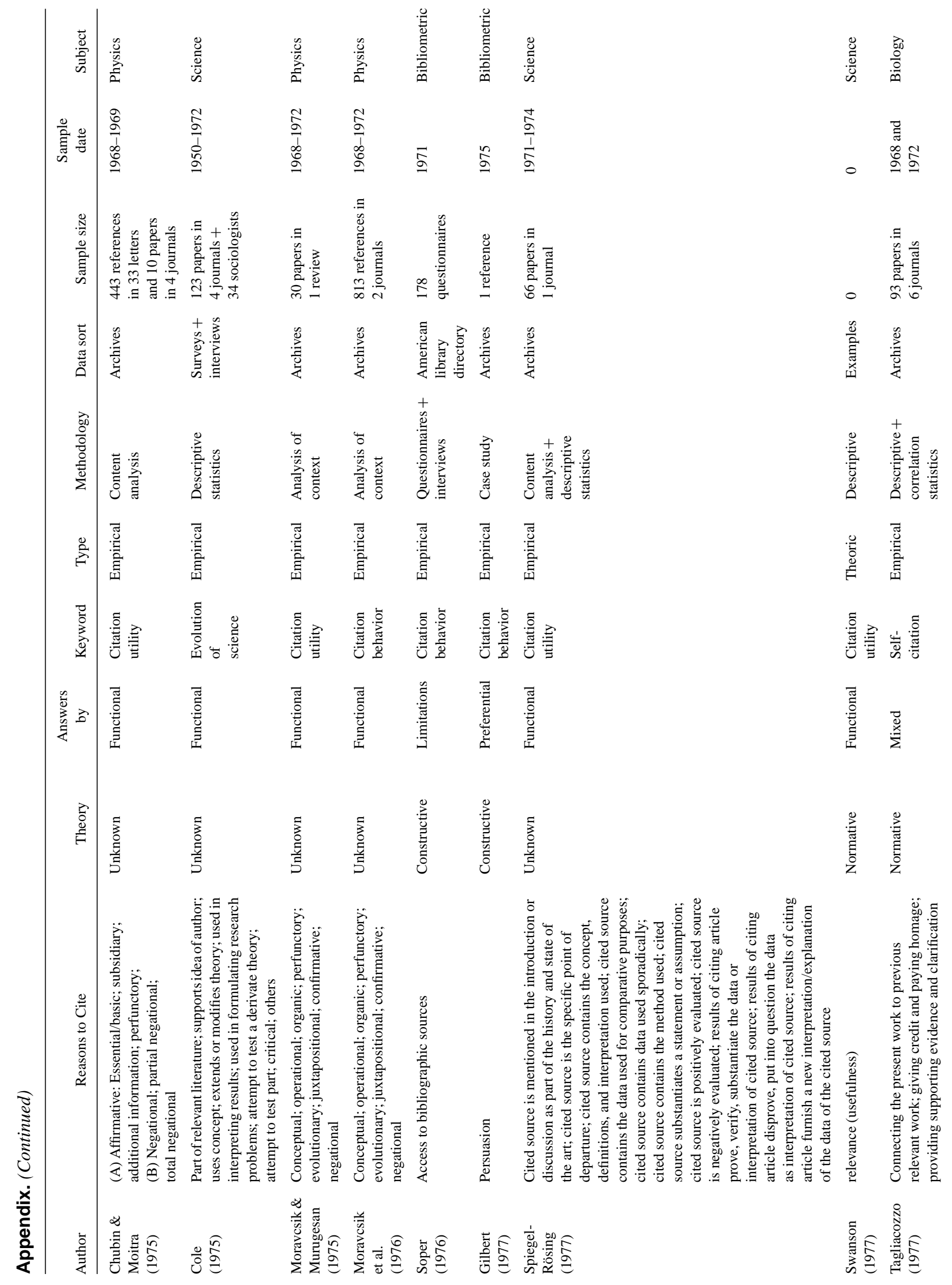

This is a preprint of an article accepted for publication in Journal of the American Society for Information Science and Technology copyright @ 2009 (American Society for Information Science and Technology) 


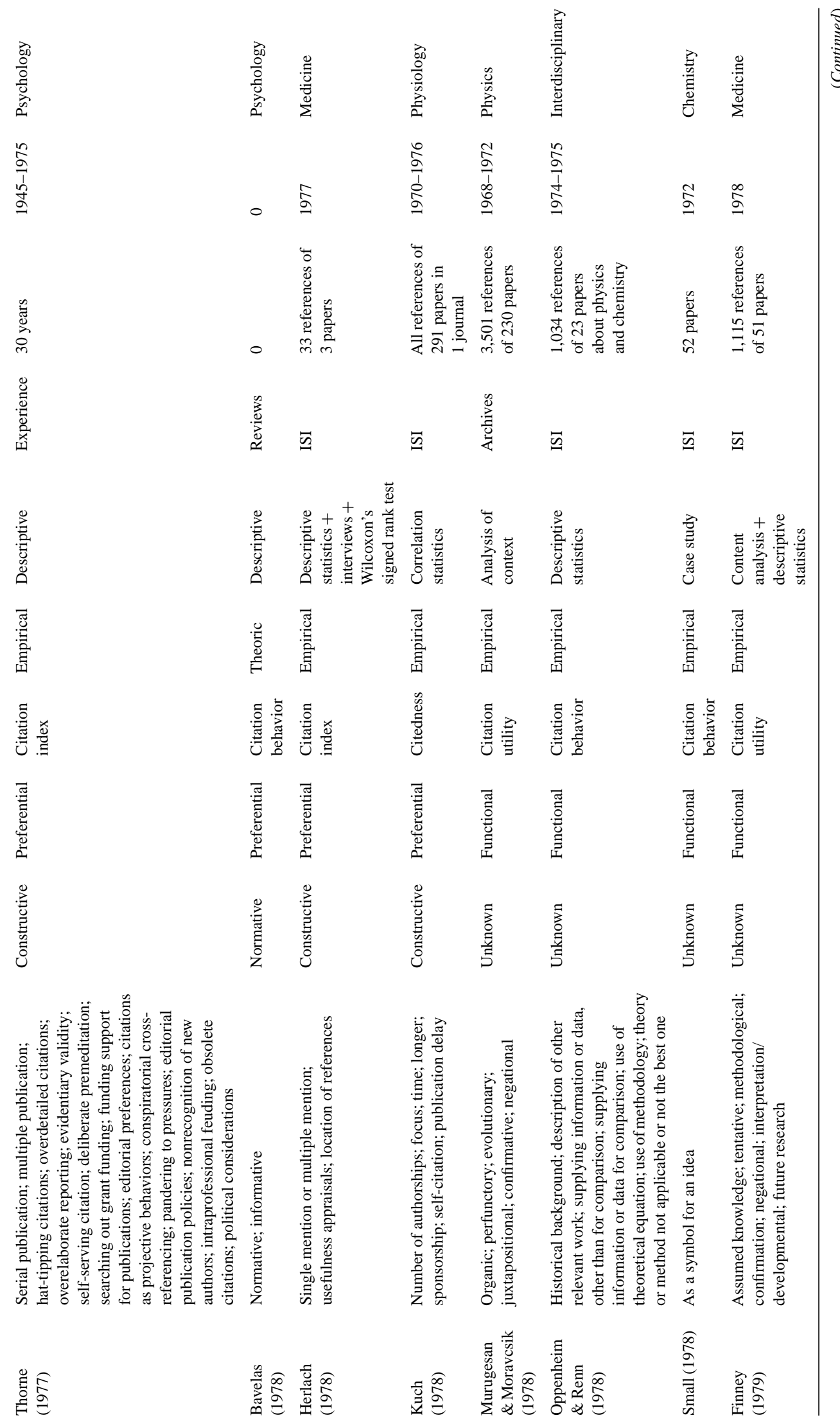




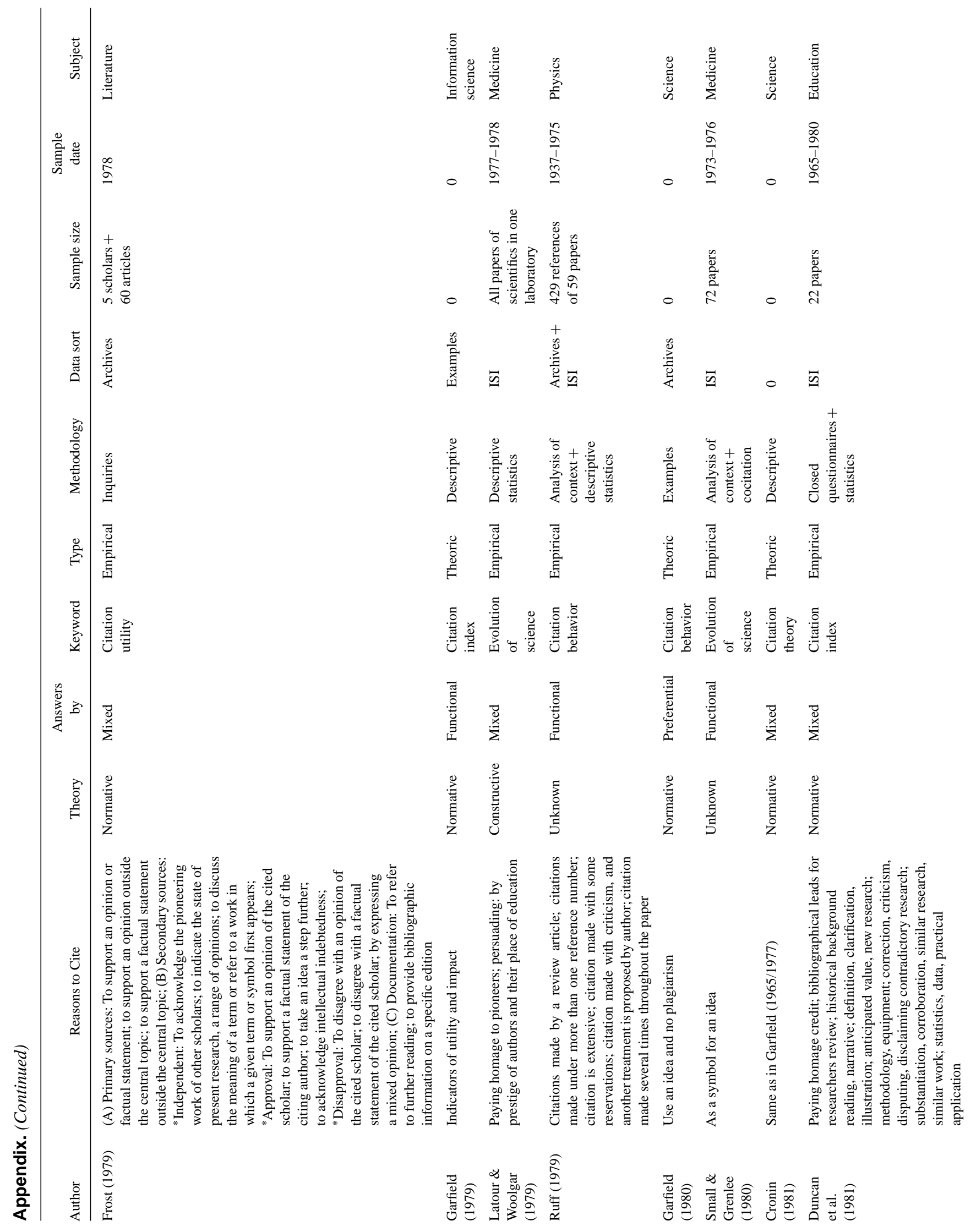

This is a preprint of an article accepted for publication in Journal of the American Society for Information Science and Technology copyright @ 2009 (American Society for Information Science and Technology) 


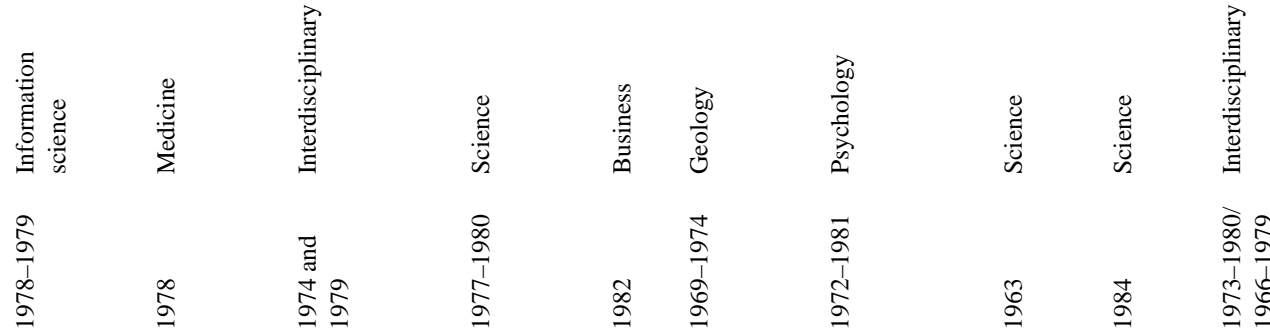

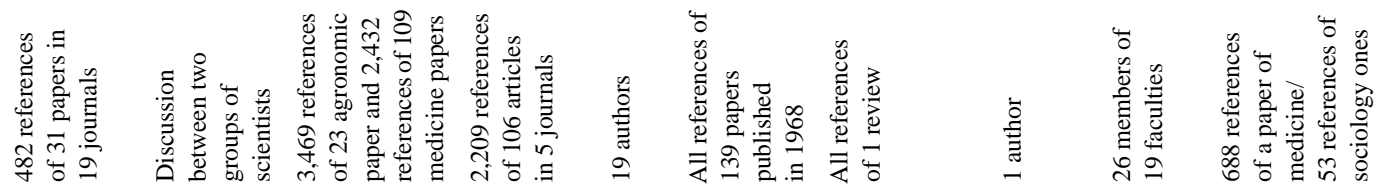

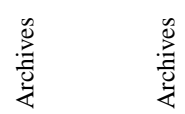

$\overrightarrow{\underline{n}}$

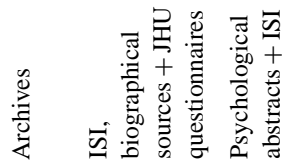

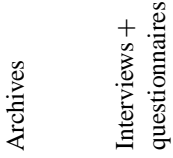

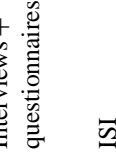

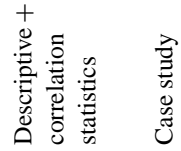

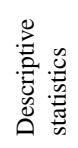

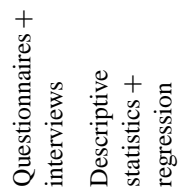

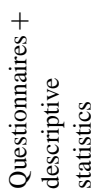

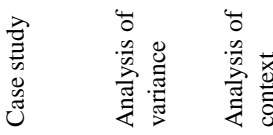

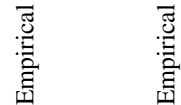

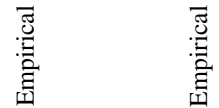

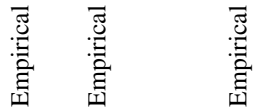

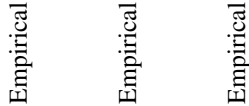

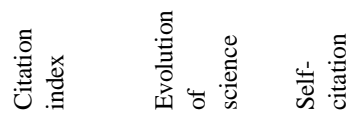

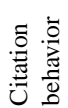

竎

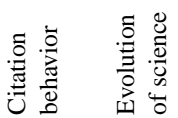

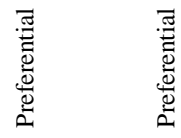

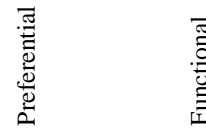

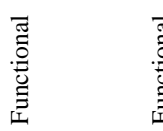

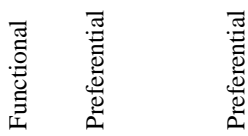

洜

总

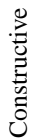

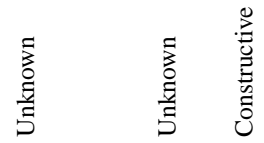

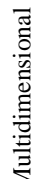
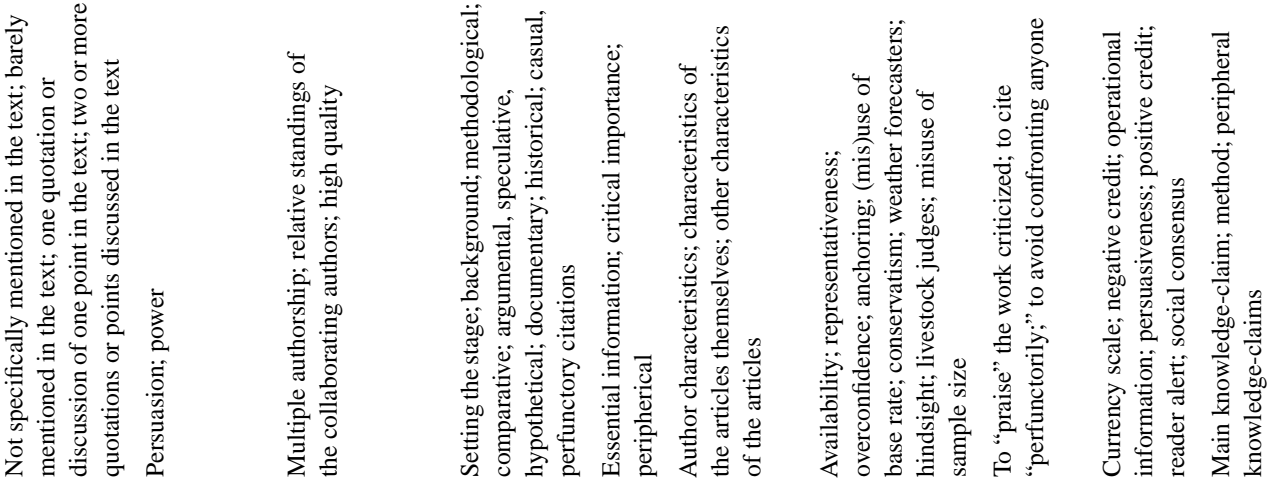

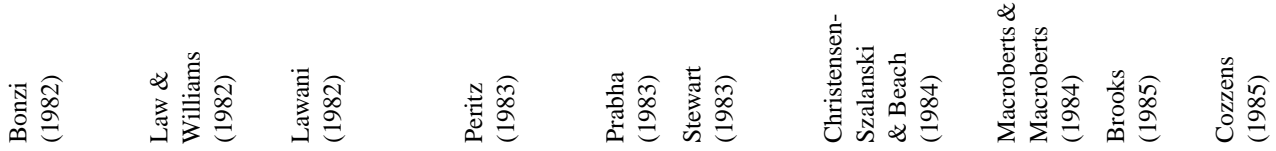




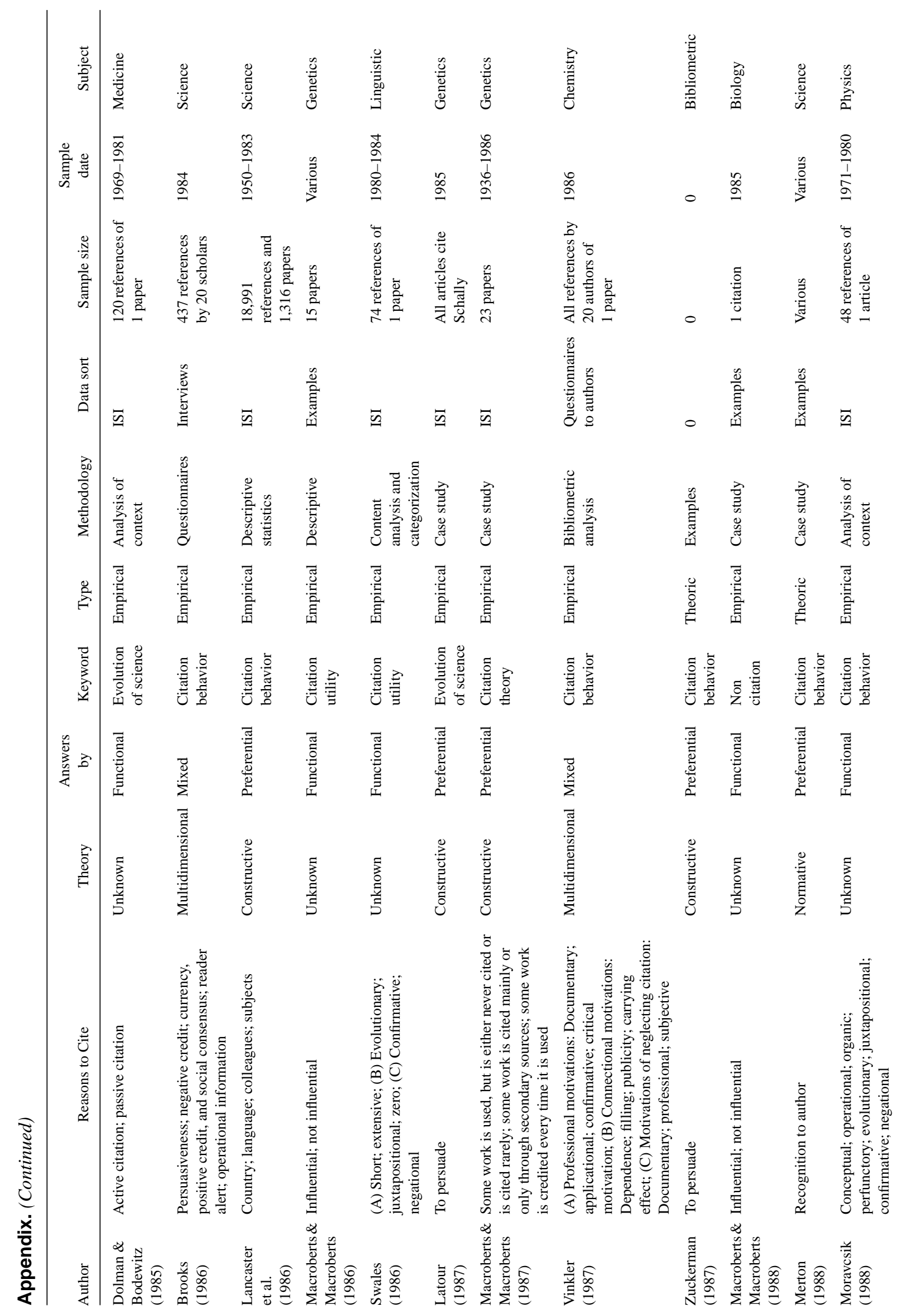


㽦

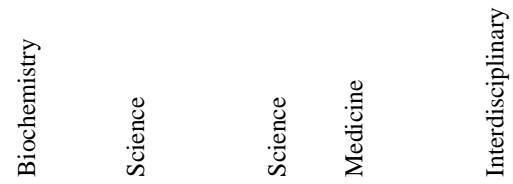

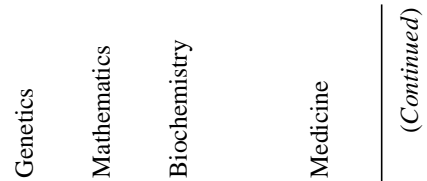

$\stackrel{\infty}{\varrho}$

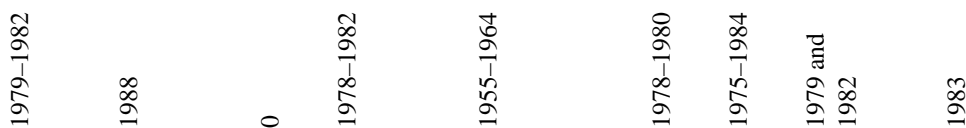

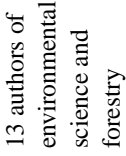

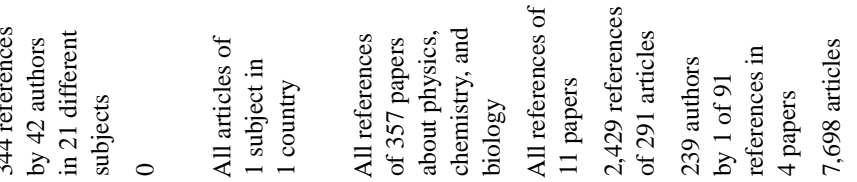

总茵氙

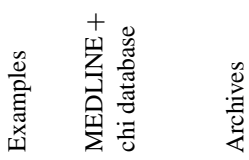

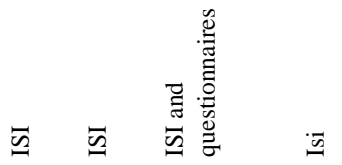

范

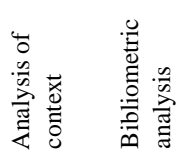

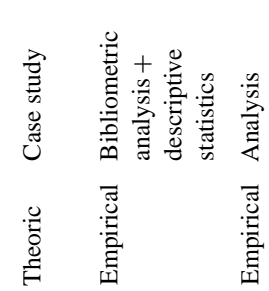

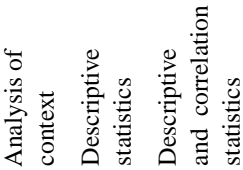

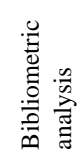

:

:

莺 $\quad$ 莺 $\quad$ :

:气 :

㫣

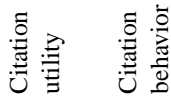

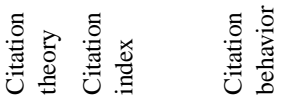

总芯

恚

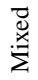

䠌

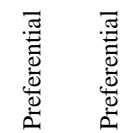

쥼

焉

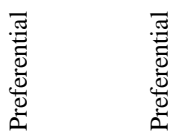

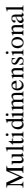

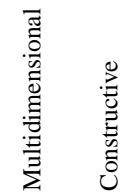

章
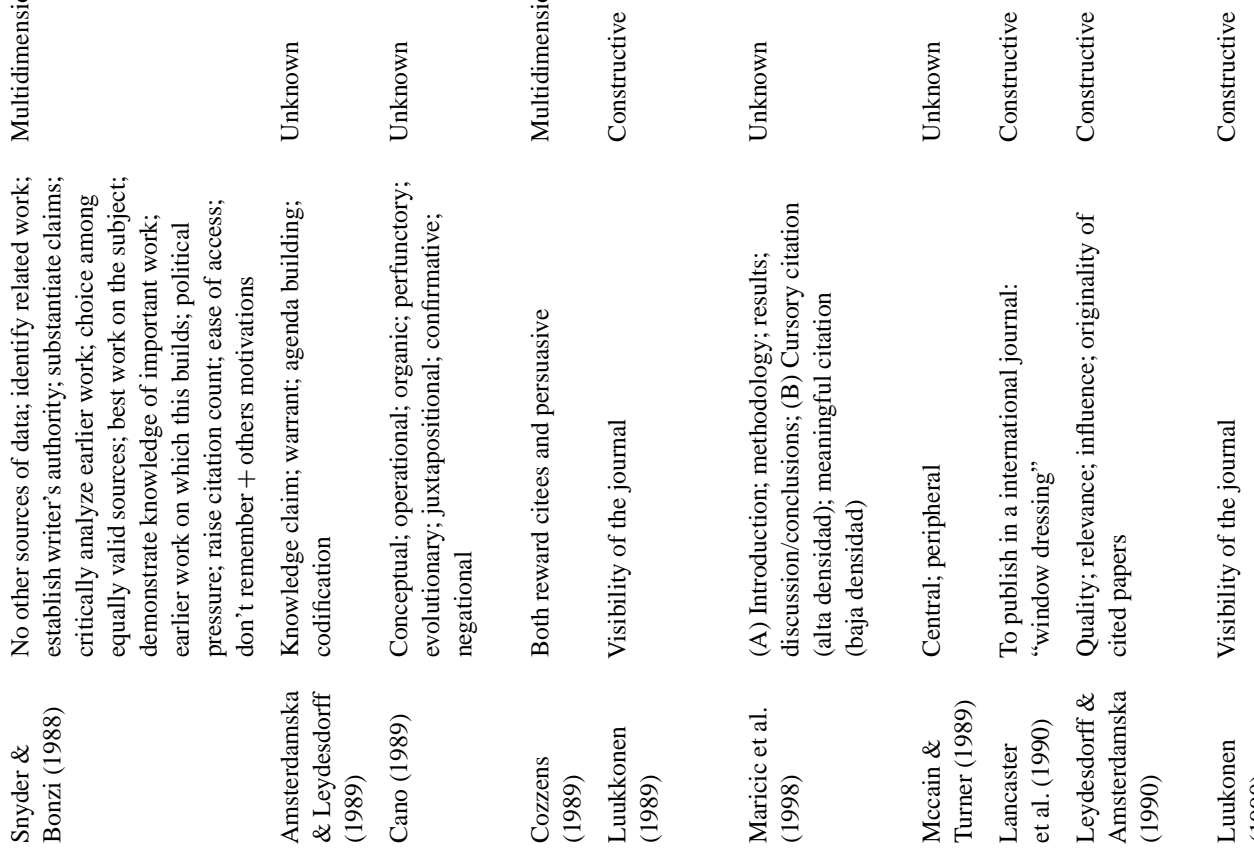

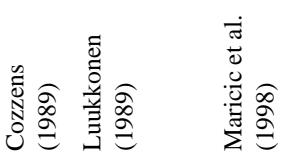

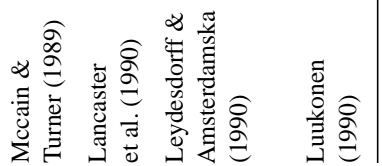




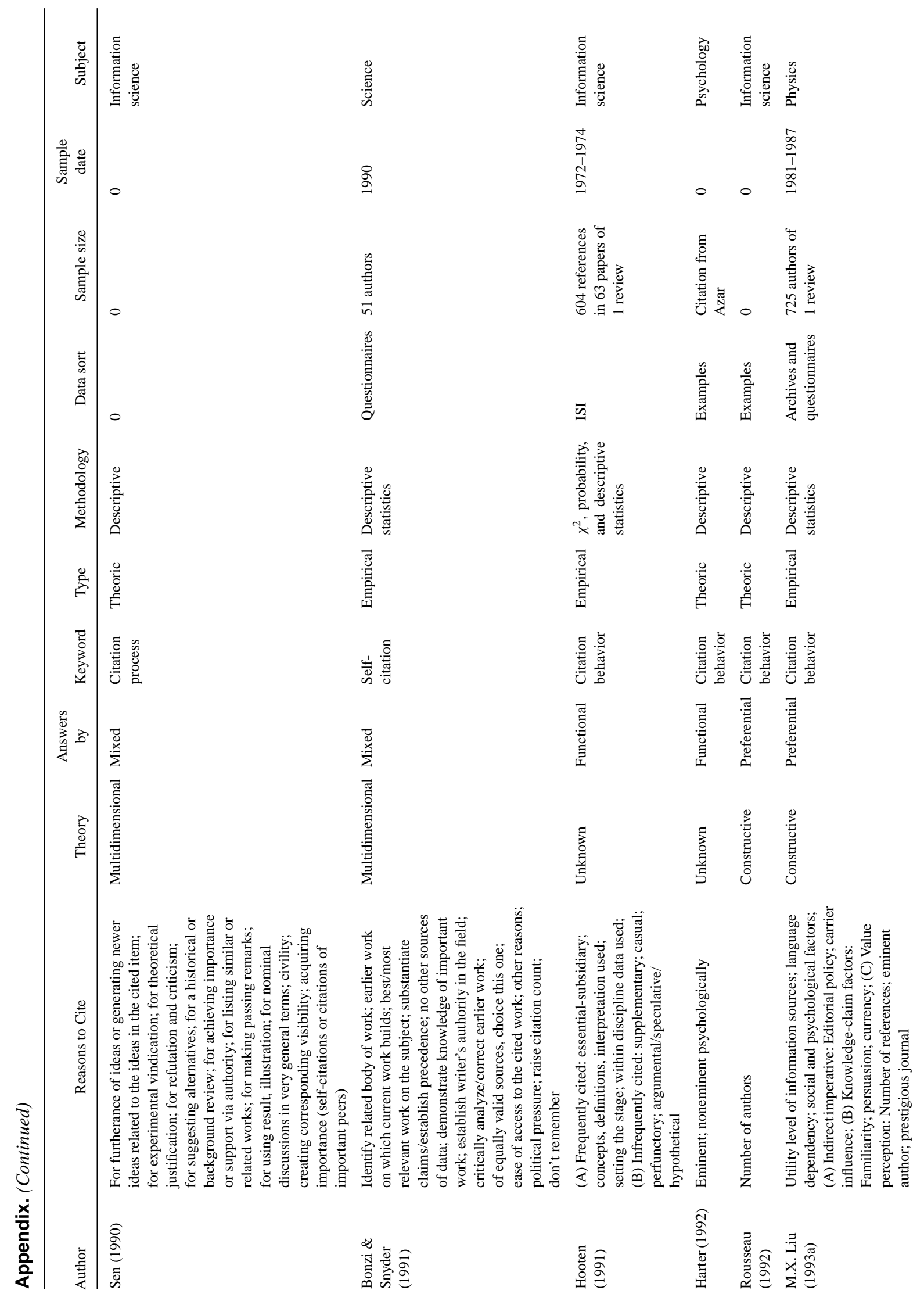

This is a preprint of an article accepted for publication in Journal of the American Society for Information Science and Technology copyright @ 2009 (American Society for Information Science and Technology) 


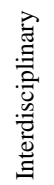

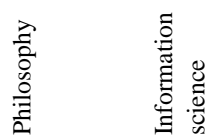

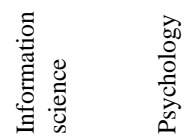

롬

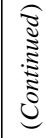

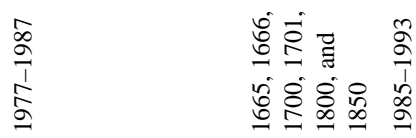

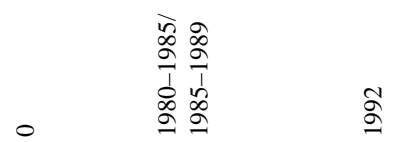

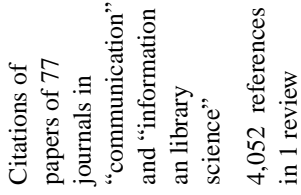

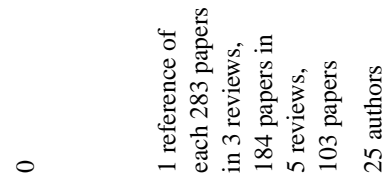

$\bar{\Omega}$

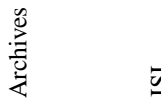

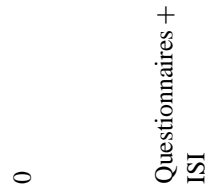

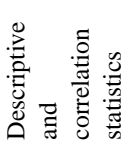

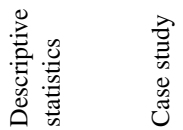

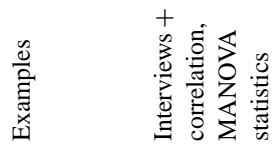

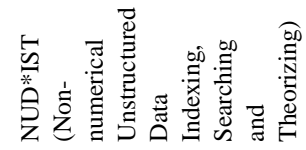

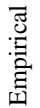

胥

苛

:

总

童

总

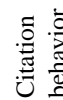

总疍

플

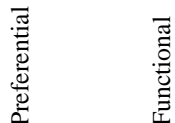

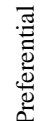

है

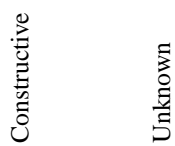

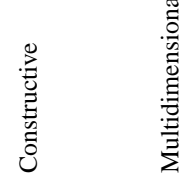

:

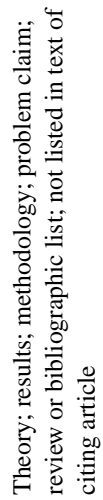

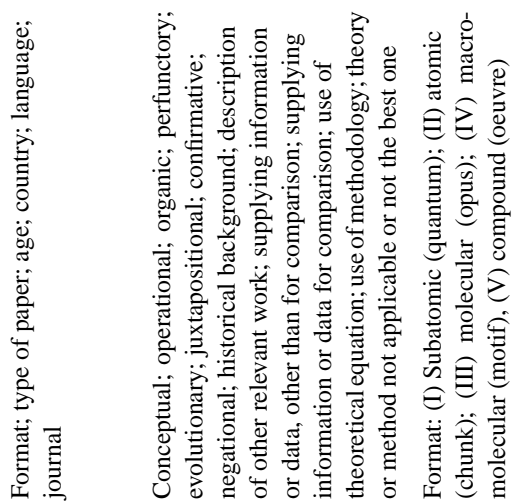

总

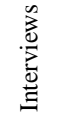

娄

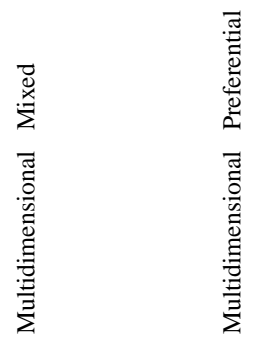

\&

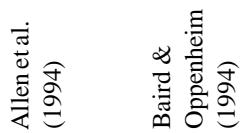

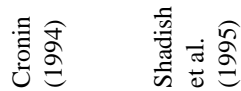

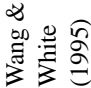




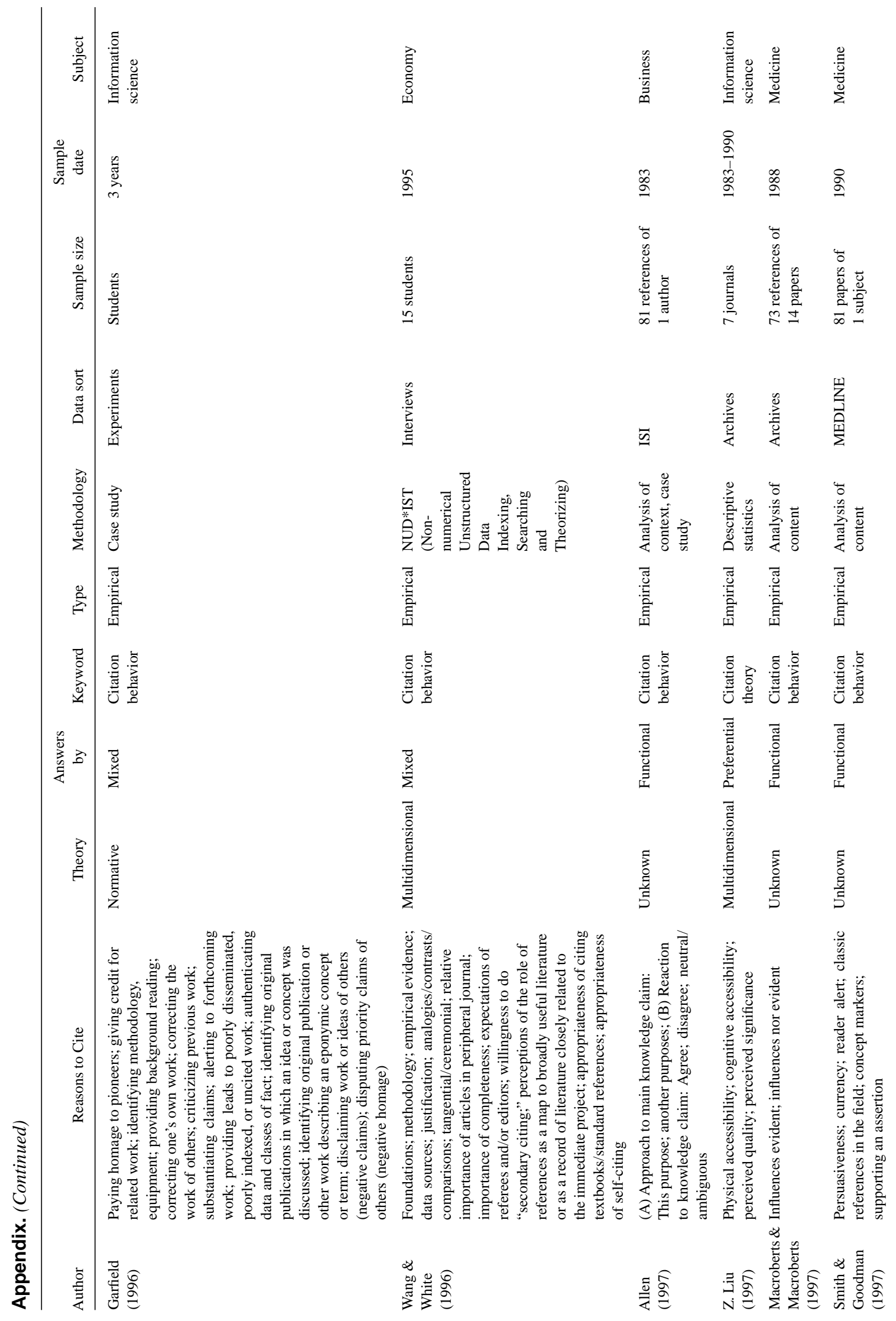




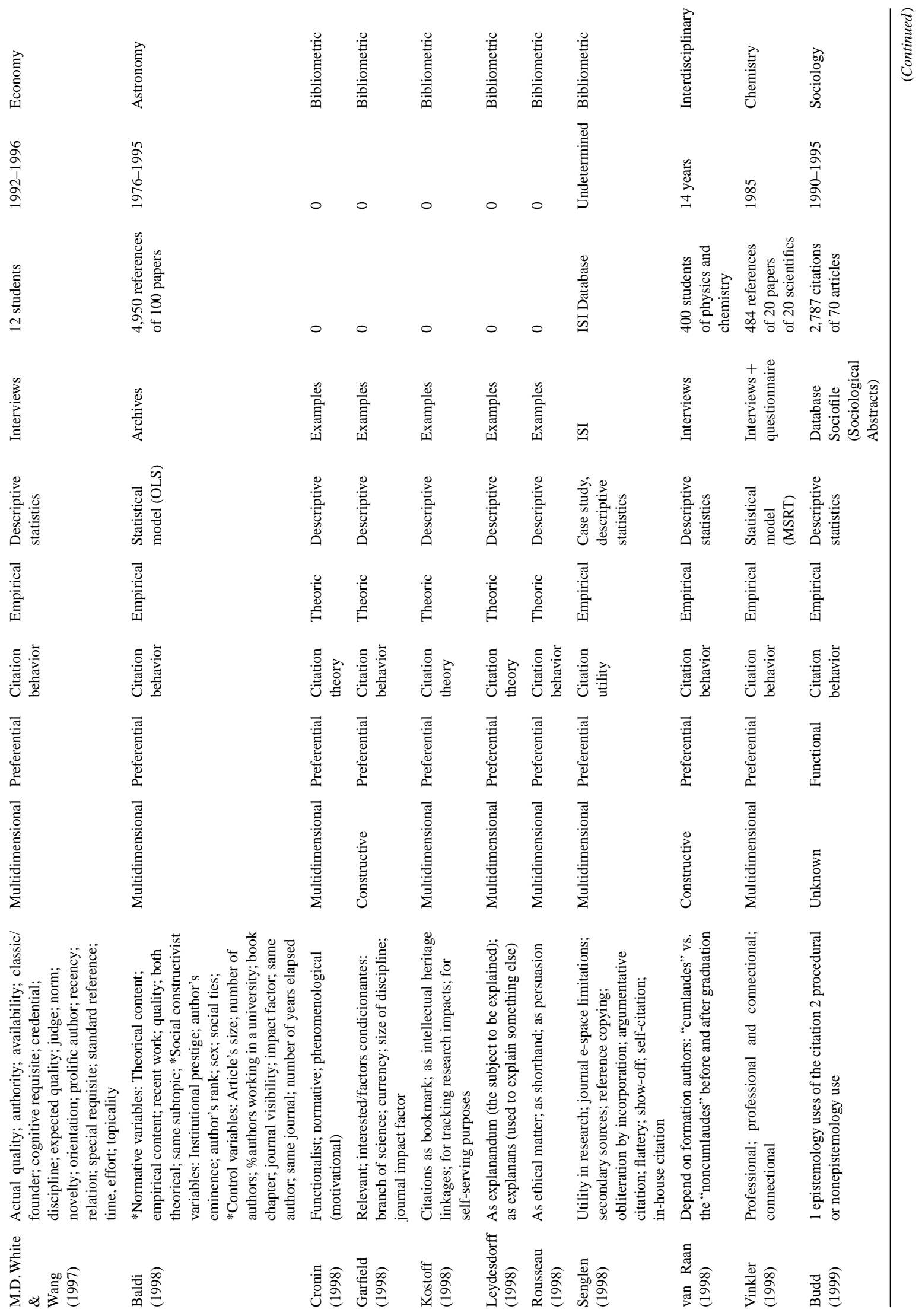




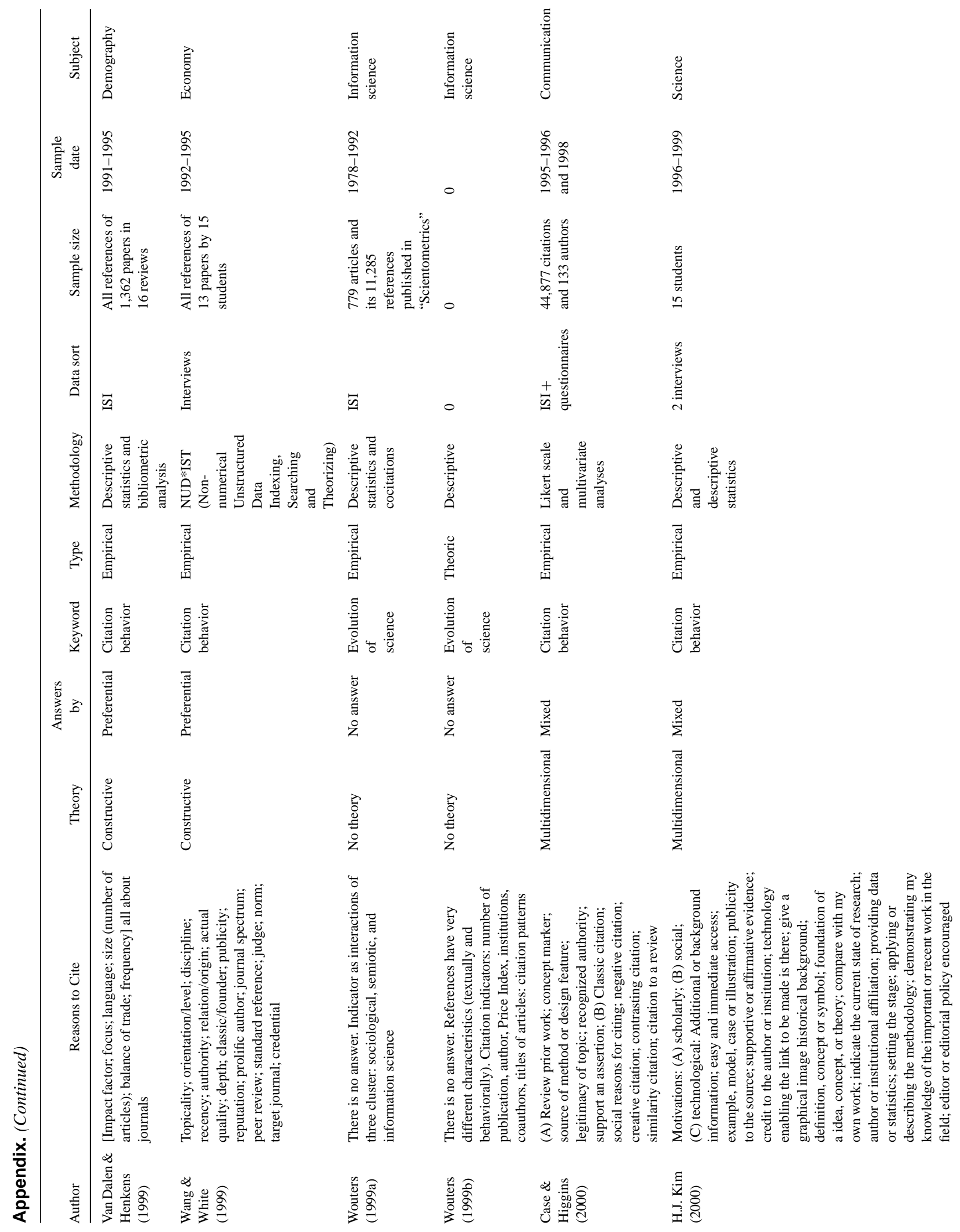


In

$\|1|\||$

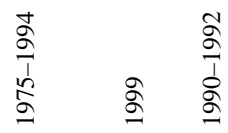

$8,1 \frac{1}{1}$

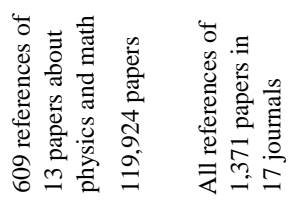

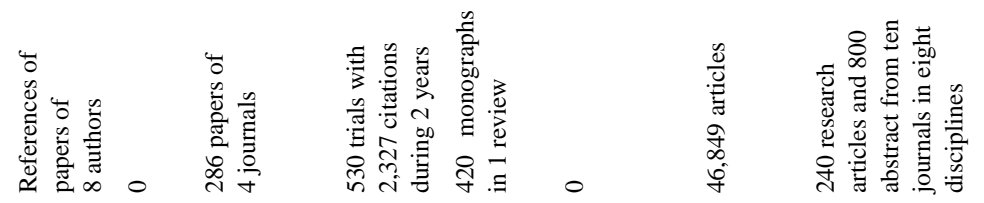

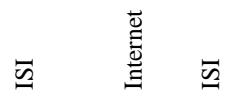

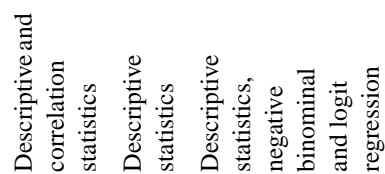

氠

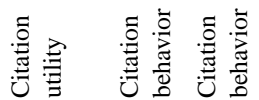

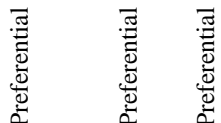

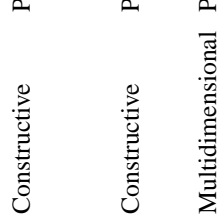

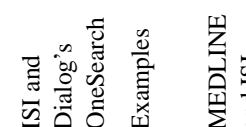

III

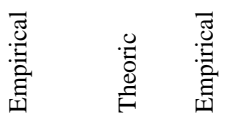

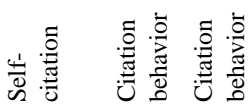

III

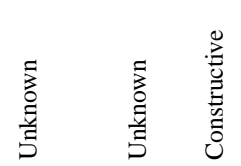

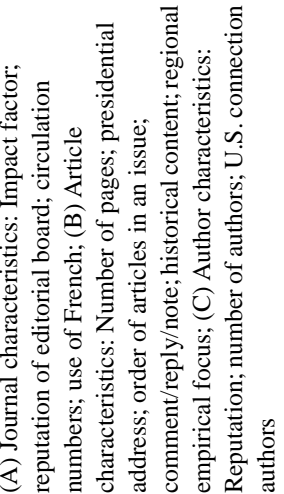

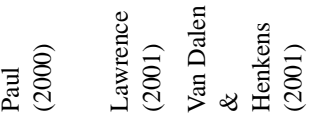

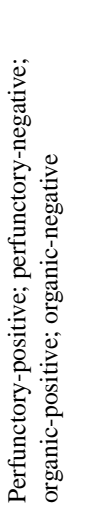

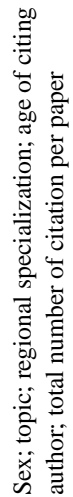

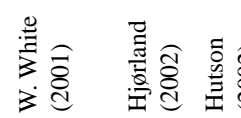

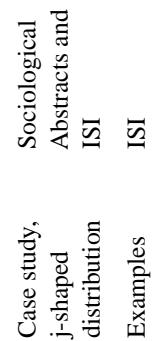

胥

氙

.

幽

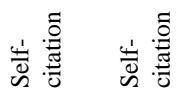

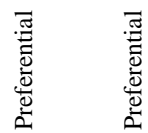

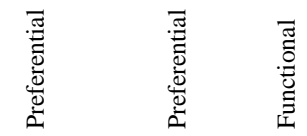

焉

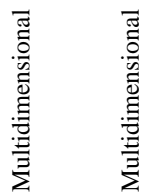

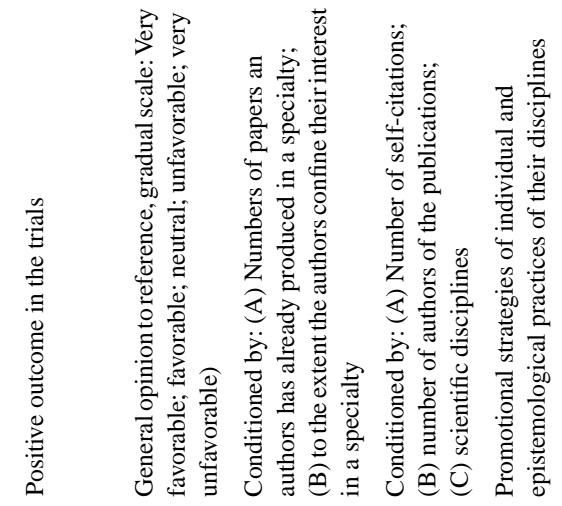

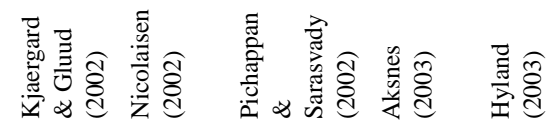




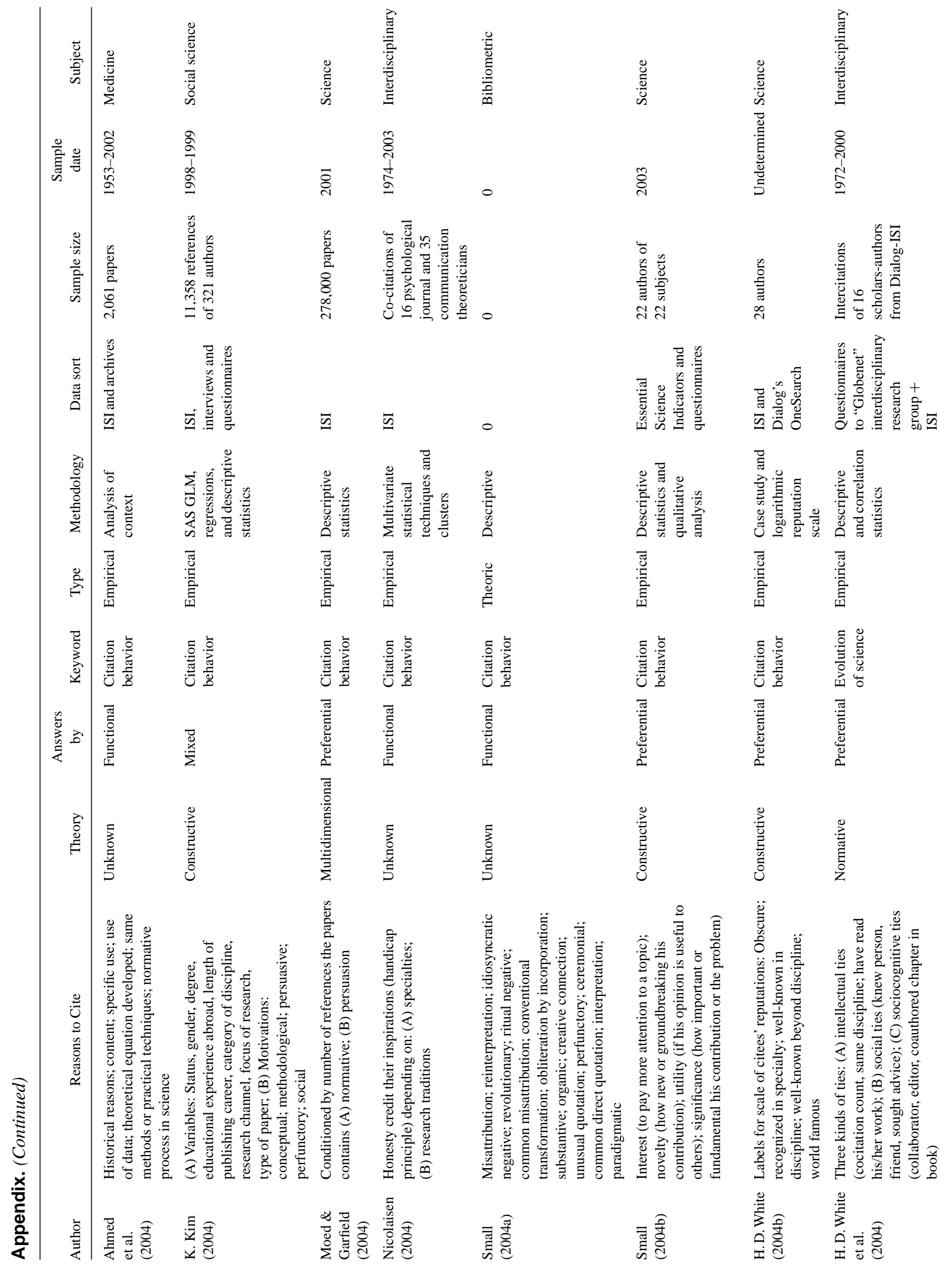




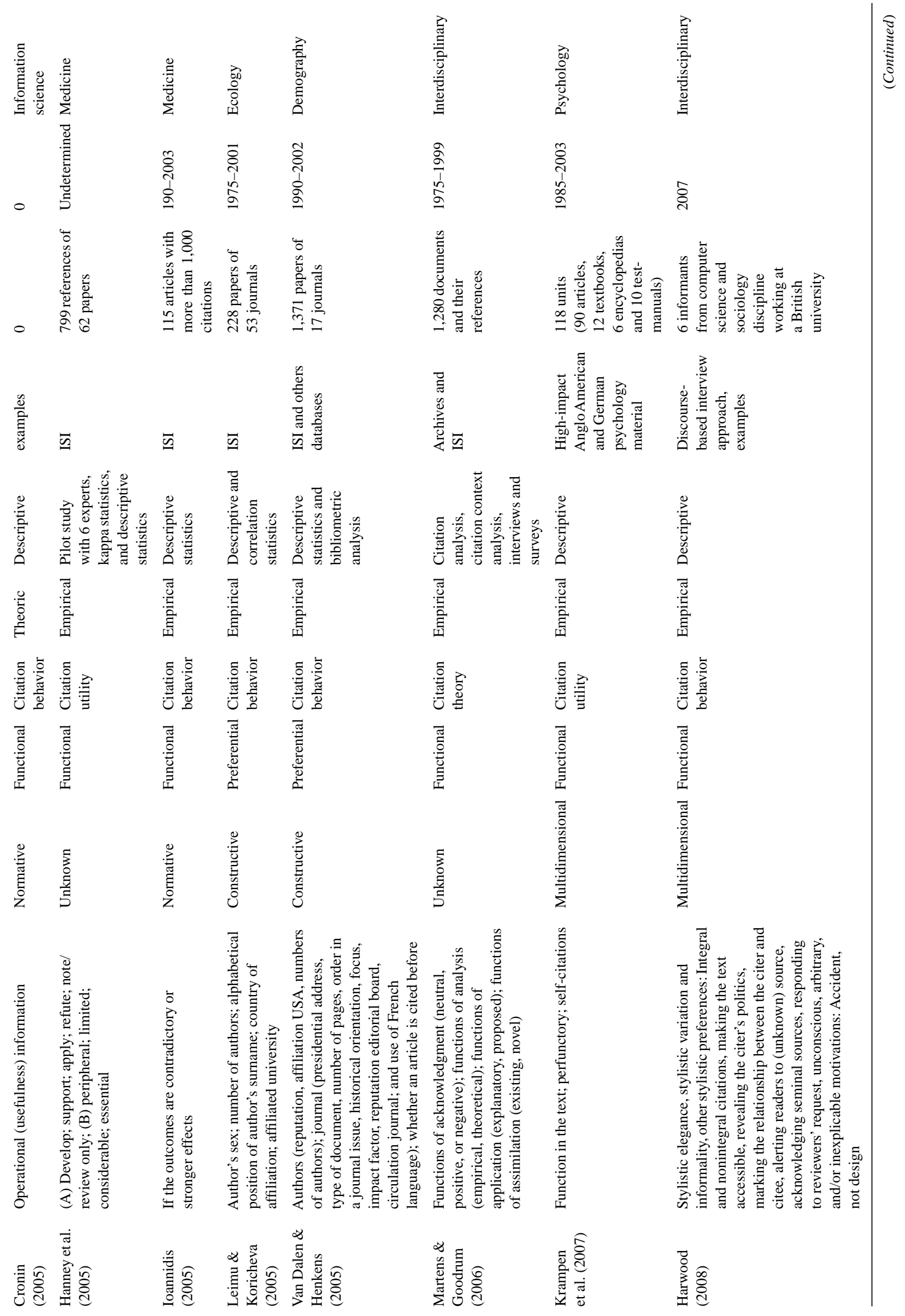

